\title{
A scenario-based MCDA framework for wastewater infrastructure planning un- der uncertainty
}

Zheng, Jun*, Egger, Christoph, and Lienert, Judit

Swiss Federal Institute of Aquatic Science and Technology, Eawag, P.O. Box 611, CH-8600 Duebendorf, Switzerland

* Corresponding author: Phone:+86 13651664592; jun.zheng@eawag.ch

Co-authors: christoph.egger@eawag.ch; judit.lienert@eawag.ch

Abstract: Wastewater infrastructure management is increasingly important because of urbanization, environmental pollutants, aging infrastructures, and climate change. We propose a scenario-based multi-criteria decision analysis (MCDA) framework to compare different infrastructure alternatives in terms of their sustainability. These range from the current centralized system to semi- and fully decentralized options. Various sources of uncertainty are considered, including external socio-economic uncertainty captured by future scenarios, uncertainty in predicting outcomes of alternatives, and incomplete preferences of stakeholders. Stochastic Multicriteria Acceptability Analysis (SMAA) with Monte Carlo simulation is performed, and rank acceptability indices help identify robust alternatives. We propose step-wise local sensitivity analysis, which is useful for practitioners to effectively elicit preferences and identify major sources of uncertainty. The approach is demonstrated in a Swiss case study where ten stakeholders are involved throughout. Their preferences are quantitatively elicited by combining an online questionnaire with face-to-face interviews. The trade-off questions reveal a high concern about environmental and an unexpectedly low importance of economic criteria. This results in a surprisingly good ranking of high-tech decentralized wastewater alternatives using urine source separation for most stakeholders in all scenarios. Combining scenario planning and MCDA proves useful, as the performance of wastewater infrastructure systems is indeed sensitive to socio-economic boundary conditions and the other sources of uncertainty. The proposed sensitivity analysis suggests that a simplified elicitation procedure is sufficient in many cases. Elicitation of more information such as detailed marginal value functions should only follow if the sensitivity analysis finds this necessary. Moreover, the uncertainty of rankings can be considerably reduced by better predictions of the outcomes of alternatives. Although the results are case based, the proposed decision framework is generalizable to other decision contexts.

Keywords: multi-criteria decision analysis; scenario planning; preference elicitation; uncertainty; sensitivity analysis 


\section{Introduction}

The wastewater infrastructure system is of core importance for water pollution control and human health. The importance of infrastructure asset management has been increasingly recognized (Ashley et al., 2008; Cardoso et al., 2012; Ugarelli et al., 2009). The current wastewater infrastructure system in industrialized countries functions well, but is aging and expensive because of increasing rehabilitation needs (Maurer et al., 2005). Infrastructure performance is stressed by demographic changes, as well as by numerous environmental pollutants (EEA, 2012) and climate change (e.g. Milly et al., 2008).

It is challenging to decide which wastewater system best fulfills sustainability requirements. Traditional centralized wastewater systems perform well, but are also criticized for their high use of water for flushing toilets, low nutrient recovery, massive costs, inflexibility, etc. (Ashley et al., 2008). Novel, promising decentralized technologies such as urine separation, graywater, or biogas systems are not yet widely spread (Larsen et al., 2013). They can potentially change the paradigm of wastewater handling, although the implementation is still a challenge due to the need of practice experience (Guest et al., 2009; Larsen et al., 2009; Larsen et al., 2016).

Many planning tools have been used to compare different wastewater infrastructure alternatives, such as life-cycle assessment (Schiller and Dirlich, 2015), qualitative assessment (Dominguez et al., 2011), and performance indicators (Makropoulos and Butler, 2010). We aim at a more comprehensive representation of the 'triple bottom line' of sustainability, namely society, economy, and the environment (Ashley et al., 2008). However, there is still no consensus on the definition of sustainability (Ashley et al., 2008; Muga and Mihelcic, 2008). The choice of indictors and their aggregation remains unsolved (Rowley et al., 2012). Secondly, stakeholders should be actively involved in public decisions to embrace a diversity of values (Reed, 2008). Thirdly, uncertainty needs to be tackled. The consequences of wastewater infrastructure alternatives are uncertain by nature. Preferences of stakeholders are seldom precisely known, e.g. because they are vague or difficult to express in numbers (Gregory et al., 2012). Fourthly, longterm planning is required to address climate change and socio-demographic developments. Therefore, an improved decision support tool is clearly necessary.

Multi-Criteria Decision Analysis (MCDA) seems capable of addressing these challenges (Belton and Stewart, 2002; Eisenführ et al., 2010; Keeney and Raiffa, 1976). There are a variety of MCDA methods, including Multi-attribute value/utility theory (MAVT/MAUT) (Keeney and Raiffa, 1976), Analytic Hierarchy Process (AHP) (Saaty, 1980), Dominance-based rough set approach (Greco et al., 2001), outranking methods (Roy, 1996), etc.

MCDA has been applied to water resource management, including water policy, strategic planning, and infrastructure selection (Hajkowicz and Collins, 2007). Keeney and Wood (1977) 
illustrated the feasibility of MAVT for long-range water resource planning. They explicitly stated that a more sophisticated analysis is needed by developing better attributes and including uncertainty. Chung and Lee (2009) used AHP to estimate weights of criteria and ranked water management alternatives with ELECTRE II , Regime, and Evamix methods. Yang et al. (2011) prioritized the alternatives for watershed management under climate change and urbanization also using ELECTRE II. Ülengin et al. (2001) selected remedy for water-crossing problem with PROMETHEE method. Kim et al. (2013) prioritized the best sites for treated wastewater instream use with Fuzzy Technique for Order of Preference by Similarity to Ideal Solution (fuzzy TOPSIS) considering various uncertainties. For sustainable wastewater management, Guest et al. (2009) argued that the lack of a socio-technological planning and design methodology is the larger problem than the availability of technology, and encouraged using MCDA. Ashley et al. (2008) devised a multi-criteria assessment framework to support asset investment decisions for wastewater systems, which however, remains largely unused (Hurley et al., 2008). Molinos-Senante et al. (2014) developed a composite indicator embracing economic, environmental and social issues to assess the sustainability of wastewater treatment, and AHP was used to assign weights to each indicator.

Each MCDA method has strengths and weaknesses (Cinelli et al., 2014). Outranking methods are widely used in practice, and promoters of ELECTRE (Bernard and Denis, 1993; Figueira et al., 2013; Roy, 1996) and PROMETHEE-GAIA (e.g. Behzadian et al., 2010; Brans et al., 1986) have developed user-friendly software, based on pairwise comparisons and outranking relations. Pairwise comparisons are possibly easier for decision-makers because they mimic intuitive decision-making, but can result in a large number of questions and may be cognitively demanding (Macharis and Springael, 2004). AHP also uses pairwise comparisons and is extremely popular (Saaty, 1980), but has been heavily criticized (Smith and Von Winterfeldt, 2004). We chose MAVT/MAUT because of its solid axioms of rationality (Reichert et al., 2015). Moreover, we follow the spirit of value-focused thinking (Dyer, 2005; Keeney, 1996), which proposes that eliciting stakeholders' preferences should be independent of the decision alternatives. This can be achieved in MAVT/MAUT, while rank reversals may occur e.g. in AHP when new alternatives are introduced or a lower ranked alternative is removed (Dyer, 1990). Moreover, MAUT is particularly suitable to manage random and probabilistic input criteria values (Reichert et al., 2015), which is relevant because many wastewater engineering models predict the performance of alternatives with uncertainty (Cinelli et al., 2014).

The application of MAUT is challenging especially when stakeholders' preferences are incorporated and several scenarios considered. Preference elicitation is cognitively demanding for respondents if difficult trade-offs have to be made (Gregory et al., 2012). Moreover, some common simplification such as the widely used additive model (see Section 2.4.2 for the definition) and linear marginal value functions do not always hold, especially for environmental deci- 
sions (Langhans and Lienert, 2016; Langhans et al., 2014). Finally, the elicitation of preferences regarding different scenarios remains unresolved (Stewart et al., 2013). A careful design of the MCDA process to incorporate stakeholders' preference is vital for successful application. This research is part of the 'SWIP'-project (Sustainable Water Infrastructure Planning, www.eawag.ch/swip), conducted within the Swiss National Research Programme NRP 61 'Sustainable Water Management' (www.nfp61.ch). Previously, we analyzed the roles of different actors in the decision (Lienert et al., 2013) and presented the structuring phase of the MCDA and the development of scenarios (Lienert et al., 2015). This paper furthers our previous research and aims at providing a practical tool to support wastewater infrastructure decisions. It deals with:

1. Eliciting stakeholders' preferences and incorporating them into MAUT;

2. Identifying robust wastewater infrastructure alternatives considering external uncertainties, and uncertainties of predictions and the stakeholders' preferences;

3. Using local sensitivity analysis to help practitioners verify the appropriateness of common simplifications, i.e. additive aggregation and linear marginal value functions; identifying which uncertainty source matters most;

4. Demonstrating the applicability of the framework in a real-world case study.

In Section 2 we describe the decision framework and its application to the case study. The MCDA elements in our previous work are briefly recalled. We then focus on the prediction of outcomes of alternatives, preference elicitation and modeling, identification of robust alternatives, and the step-wise sensitivity analysis. Section 3 provides the results of the predictions, the elicited preferences, and the evaluation of alternatives for all stakeholders and four future scenarios. Section 4 presents the sensitivity analysis results. In Section 5, we discuss interesting findings, lessons learnt, and recommendations for using the decision framework. We end with some conclusions.

\section{Materials and methods}

\subsection{A structured decision analysis procedure}

We followed a standard MCDA procedure (Belton and Stewart, 2002; Eisenführ et al., 2010; Keeney and Raiffa, 1976) (Figure 1). Structuring the decision included clarifying the context, stakeholder selection, and problem formulation (define scenarios, alternatives, objectives hierarchy, and attributes). These steps for the case study are described in detail in (Lienert et al., 2013; Lienert et al., 2015); we briefly recall the relevant results in Section 2.2. This paper focuses on the next steps, namely assessing the outcomes of alternatives, preference elicitation, MCDA evaluation, sensitivity analyses, and stakeholder feedback. We present details in the supplementary material (SM), which intends to help interested readers to understand and maybe use the procedure for their own decision. 


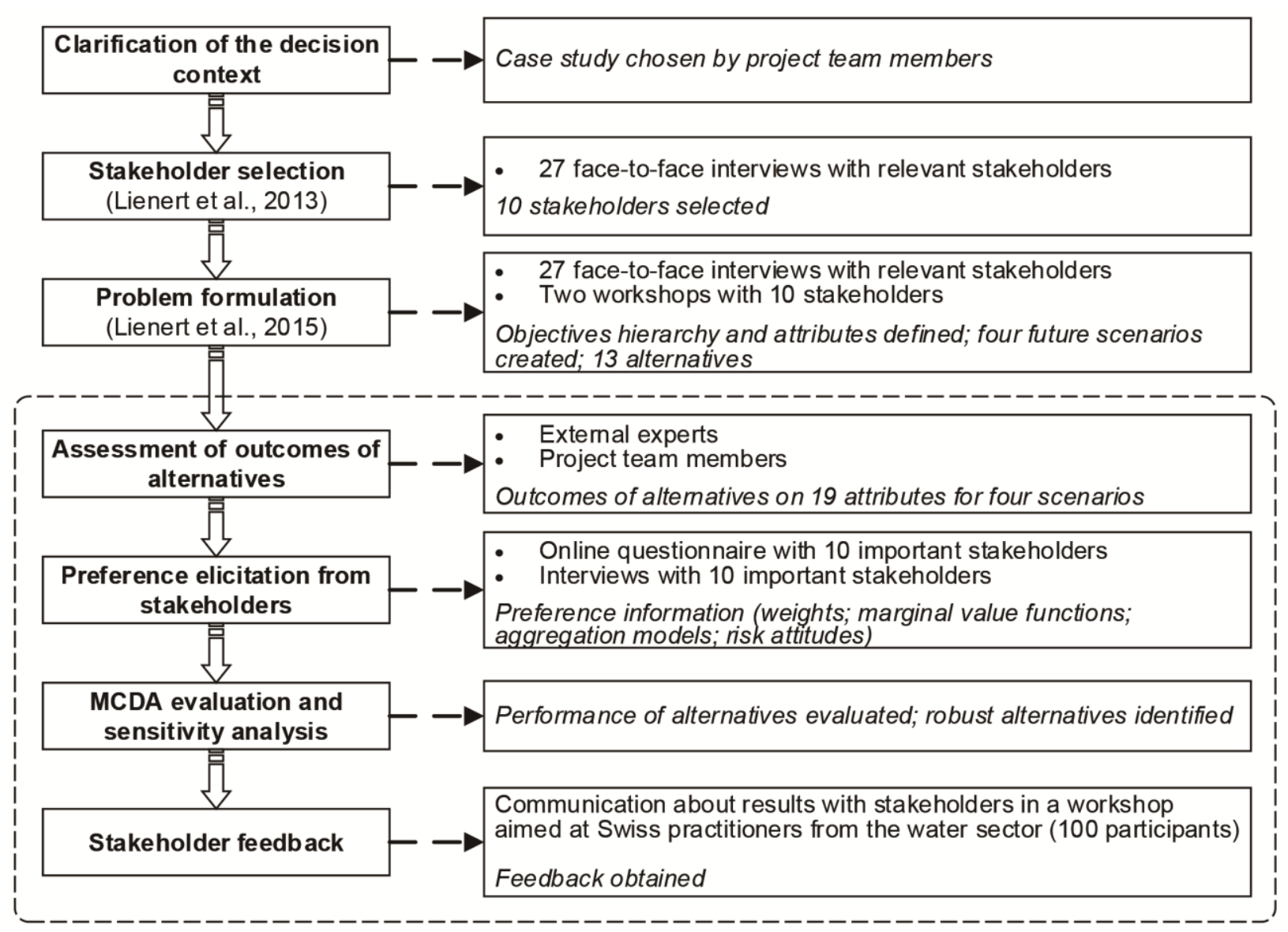

Figure 1. The structured decision procedure: people involved, related activities, and outcomes for the case study. This paper focuses on the steps within the dashed border.

\subsection{Case study}

The case study is located near lake Greifensee, in a rural agglomeration of Zürich, Switzerland. There are four relevant municipalities with about 24'200 inhabitants in total (year 2010). The three current wastewater treatment plants (WWTP) are running close to their capacity limits. The average age of sewers is around 33 years. Lake Greifensee is one of the few Swiss lakes which still suffer from phosphate eutrophication due to wastewater and extensive agriculture (AWEL, 2006). We identified stakeholders very systematically, by combining a stakeholder analysis with social network analysis; over 40 actors play a role in water infrastructure planning (Lienert et al., 2013). We identified ten important stakeholders from different decisional levels (local, cantonal, and national), covering different sectors (engineering practice, administration \& politics, science; Tab. 1) for this study.

Table 1. Selected stakeholders $(\mathrm{SH}) . \mathrm{WWTP}=$ wastewater treatment plant; $\mathrm{WW}=$ wastewater

\begin{tabular}{lll}
\hline No. & Entity/ responsibility & Decision level \\
\hline SH1 & WWTP engineer & Local \\
SH2 & Joint WWTP authority & Local \\
SH3 & Municipal administration for WW & Local \\
\hline
\end{tabular}




\begin{tabular}{lll}
\hline SH4 & Urban drainage engineer & Local \\
SH5 & Sewer maintenance company & Local \\
SH6 & Cantonal office for landscape \& nature & Cantonal \\
SH7 & Cantonal agency for waste, water, energy and air & Cantonal \\
SH8 & Swiss water association & National \\
SH9 & Federal office for the environment FOEN & National \\
SH10 & Researcher of urban water management & National \\
\hline
\end{tabular}

We adapted four Swiss development scenarios (http://www.nfp54.ch/) to the case study in a stakeholder workshop for 2010-2050 (Tab. 2), based on exogenous drivers (e.g. population growth, urbanization, and taxable income). Some of the scenarios appear extreme, but are internally consistent and plausible storylines about possible socio-demographic development.

Table 2. Four future Scenarios, adapted from (Lienert et al., 2015).

\begin{tabular}{ll}
\hline Name & Description \\
\hline $\begin{array}{l}\text { Status Quo } \\
\text { Quality of Life }\end{array}$ & $\begin{array}{l}\text { Long-term projection of current situation. 24'200 inhabitants and low increase in urbanization and income (0.4\% per year). } \\
\text { moderate population increase (29'000 inhabitants in 2050). }\end{array}$ \\
Doom & $\begin{array}{l}\text { Difficult situation of Switzerland. Slight population decline (23'000 inhabitants in 2050); strong financial pressure (-1.5\% } \\
\text { income decrease per year). }\end{array}$ \\
Boom & $\begin{array}{l}\text { Very prosperous situation. Massive population growth (200'000 inhabitants in 2050), so dense urban and sewer network } \\
\text { expansion is foreseen. Rapid economic growth (4\% per year). }\end{array}$ \\
\hline
\end{tabular}

Substantial effort was made to devise a generic objectives hierarchy, applicable to other cases concerning sustainable wastewater infrastructure. Five top-level objectives were judged as fundamental to achieve 'Sustainable wastewater infrastructure' (Sustainable WWI): intergenerational equity (Equity), protection of water and other resources (Protection), safe wastewater disposal (Safe WW disposal), high social acceptance, and low costs (Lienert et al., 2015). Equity refers to whether we shift the rehabilitation burden to the next generation by neglecting maintenance and repairs and describes the flexibility of the infrastructures to future adaptations. Protection represents the conservation of surface and ground water resources, e.g. from chemical pollution, and the efficient use of nutrients and electrical energy. Safe WW disposal means the hygienic disposal of wastewater to avoid people getting ill and the system reliability to prevent flooding. Social acceptance uses indicators to cover managerial and infrastructure aspects that affect the acceptance by end users and the local community. Low costs stands for all expenses for the wastewater infrastructures, including capital and running costs (operation, maintenance), and whether costs increase each year. These five main objectives are broken down to sub-objectives until they can be quantified by 19 measurable attributes (Fig. 2; Tab. A.1). 


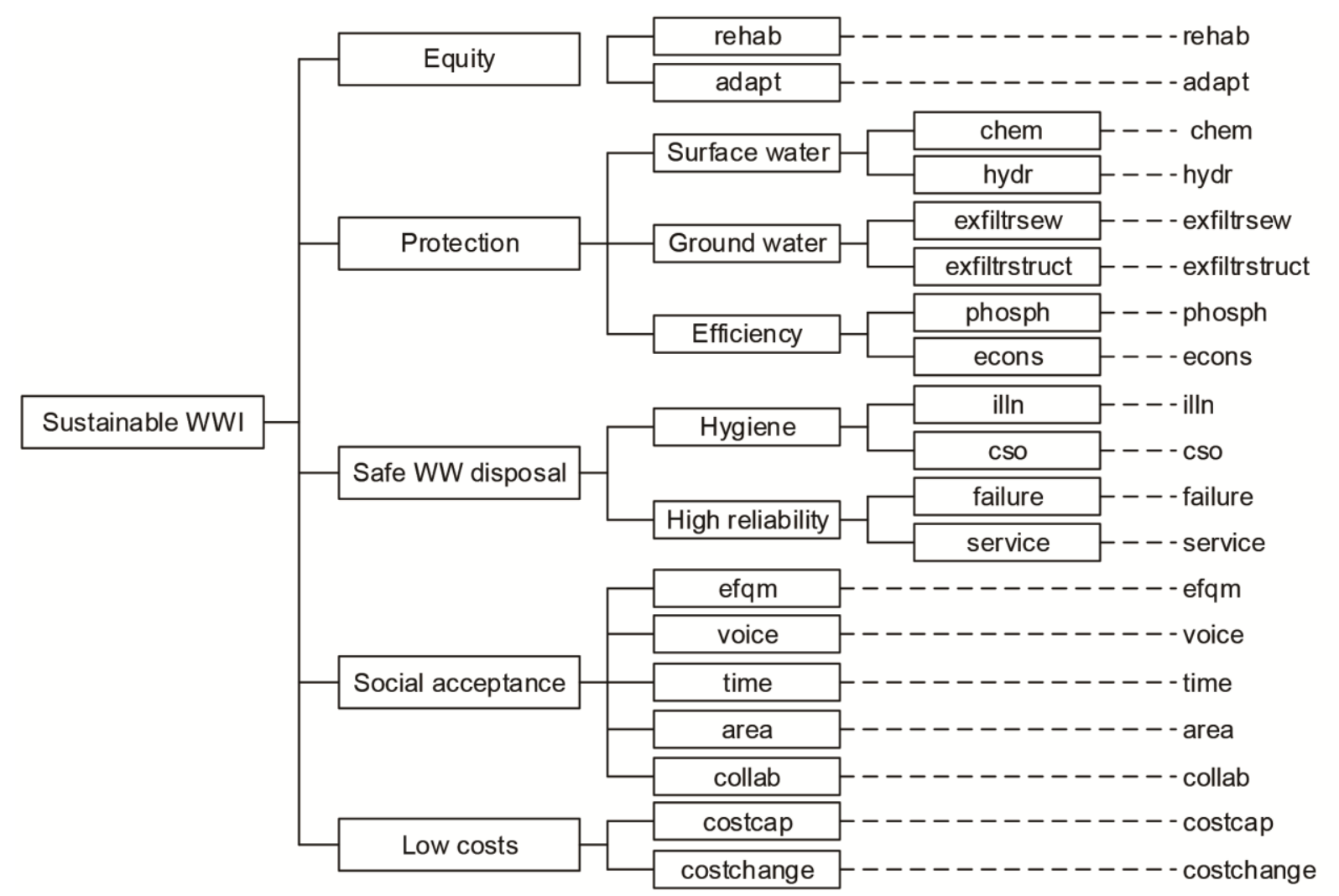

Figure 2. Objectives hierarchy of wastewater infrastructure planning. Boxes represent fundamental objectives (see supplementary material, Section SM-1.1 for details) which are described by sub-objectives. The lowest level sub-objectives (the last right boxes) are measured by attributes (text far right). WWI= Wastewater infrastructure; WW= Wastewater; further abbreviations see Appendix Table A.1.

The ten stakeholders also created 13 decision alternatives with the 'strategy generation table' approach (Howard, 1988) in a workshop (Tab. 3). These differ on five aspects: (1) organizational structure, sector cooperation and management; (2) rehabilitation, operation, and maintenance; (3) drainage system; (4) stormwater handling; and (5) wastewater and stormwater treatment (see Tab. SM-2 for full definition).

Table 3. Summary of decision alternatives. Adapted from (Lienert et al., 2015); IKA = an intercommunal agency manages the infrastructure, WWTP = wastewater treatment plant, WW = wastewater.

\section{No. Description}

A1a Private firm provides centralized full-service for entire region; service as today but with micropollutant removal at WWTP (high environmental protection). $10 \%$ of length of pipes in very bad condition; rehabilitated according to prioritization.

A1b As A1a, but provider is IKA.

A2 IKA provides centralized full-service, but different rehabilitation strategy than A1: rehabilitation only when cumulative length of pipes in very bad condition exceeds $10 \%$.

A3 Gray water is treated locally and fed into water supply tank, rest is treated centrally. Only repairs, but no rehabilitation, and only upon urgent need for action.

A4 Mixed responsibilities with minimal community service; decaying central infrastructures in core area; in outskirts wastewater is decentrally treated with cheap technologies, e.g. septic tanks; municipal collection service. Rehabilitation strategy as A3. 


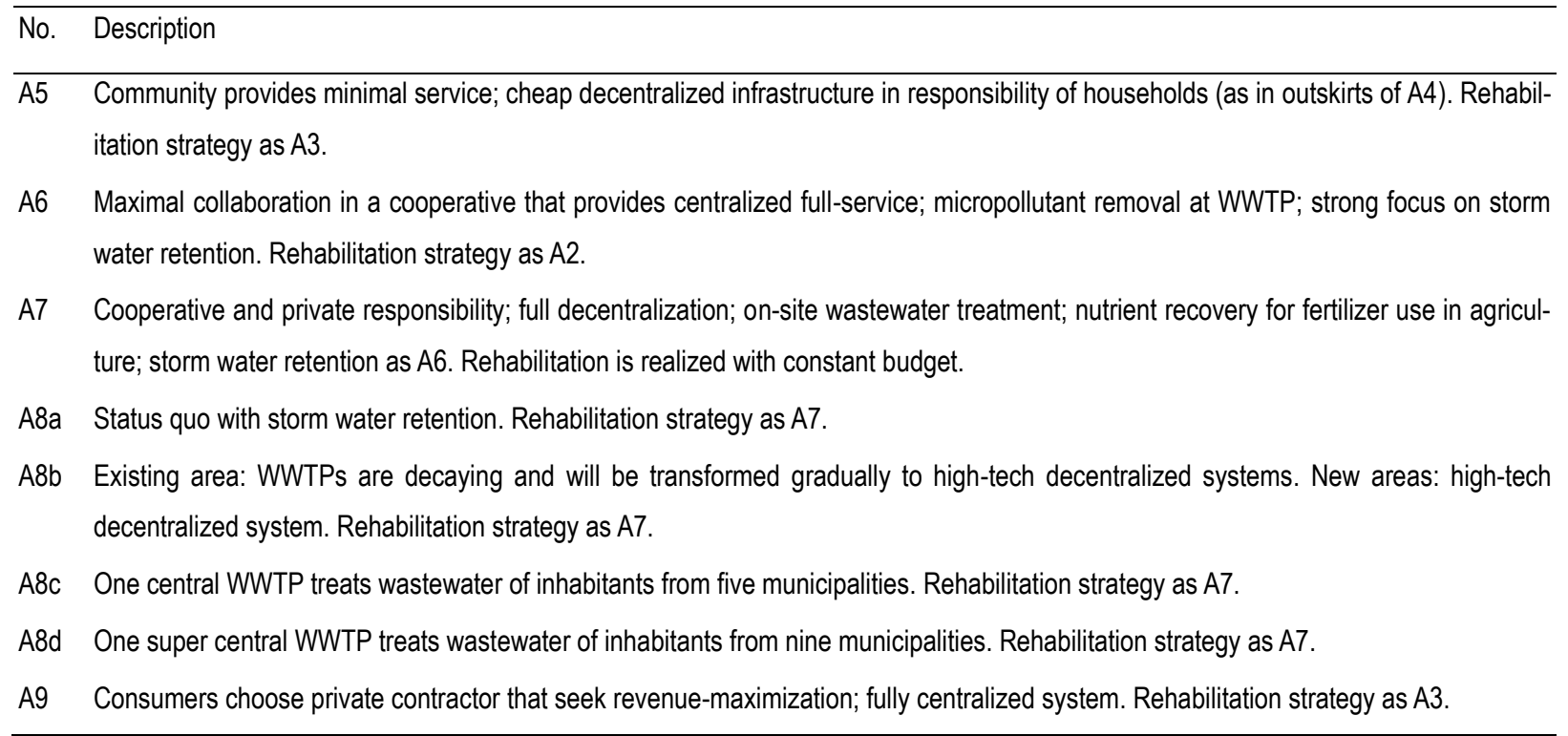

\subsection{Assessing the outcomes of alternatives in four future scenarios}

The outcomes of the alternatives were predicted based on expert judgments (e.g. flexibility of infrastructure to future adaption, attribute 'adapt', see Appendix Tab. A.1), literature reviews (e.g. net energy consumption for wastewater treatment and transport, 'econs'), engineering models (e.g. realization of rehabilitation demand, 'rehab'), or a mix of these methods, depending on best available information (see Tab. SM-1 in SM for details of prediction methods).

Wherever possible, and especially for water quality aspects, we relied on predictions of scientific models. This involved sound models to estimate the hydraulic performance and decay of sewer networks (Egger and Maurer, 2015; Egger et al., 2013) affecting several objectives (Fig. 2). Pollutants from wastewater sewers may leak into the soil and contaminate ground water (Reynolds and Barrett, 2003). Structural failures of sewers such as collapses reduce the system's reliability (Sægrov, 2005). In case of wastewater systems with insufficient capacity, receiving waters may suffer from combined sewer overflows (CSOs), where untreated wastewater containing pollutants and pathogens is discharged directly during heavy rain events (Weyrauch et al., 2010). All these are potential risks for human health, animals, aquatic plants, and the ecosystem (ten Veldhuis et al., 2010). Additionally, urban flooding is affected by altered precipitation, sewer design, and drainage area properties (Egger and Maurer, 2015; Willems et al., 2012). We used prediction models that consider these issues to estimate pollution levels and the chemical state of water bodies. The output was assessed by an evaluation model based on MAVT (Schuwirth et al., 2012b). Hereby, the estimated level of each substance (a set of nutrients and pesticides) was classified into one of five quality categories; the results of each substance were then integrated to a comprehensive indicator of the chemical state.

Prediction uncertainties mainly stemmed from divergent and uncertain knowledge, and varia- 
bility of the model processes. If predictions ranged between maximum and minimum realizations, uniform distributions were used to characterize their uncertainty. Other predictions were affected by model parameter uncertainty and the stochacity of the underlying processes represented by empirical samples.

\subsection{Eliciting preferences of stakeholders}

An information letter was sent by post to the ten stakeholders, containing a brief description of the project, the MCDA methodology, and the five fundamental objectives. Each objective was described with the same text length (ca. 200 words, Section SM-1.1). Attribute definitions and ranges were given in the annex. The stakeholders were then asked to complete an online questionnaire, to quantitatively elicit the weights of objectives and sub-objectives. Two weeks after the letter, face-to-face interviews were conducted individually with each stakeholder by a MCDA-analyst and a psychologist. Hereby, the weights elicited online were confirmed or adapted. Then, other preferences were elicited, namely marginal value functions, risk attitudes, and aggregation models. The interview took approximately three hours. After the interview, a detailed protocol was sent to the stakeholders for confirmation. We elicited weights independent of scenarios for simplicity and also assuming that we can only make decisions based on our preference today for all unknown futures (Goodwin and Wright, 2001).

\subsubsection{Eliciting weights}

We used a variant of the SMART/SWING-method to elicit weights (Mustajoki et al., 2005). This was developed to ease weight-elicitation and facilitate its implementation online. At each level of the objectives hierarchy, four types of questions were repeated (Tab. 4). For online elicitation, the questions were organized top-down, i.e. the five main objectives were assessed first, followed by the lower-level objectives and attributes, to avoid the 'splitting bias' (Pöyhönen et al., 2001). The questionnaire was implemented by Qualtrics Online Survey Software (http://www.qualtrics.com/). We analyzed answers before the face-to-face interviews.

Table 4. Questions of weight elicitation (see Section SM-3.1.1 in the supplementary material for an example of implementation in the online questionnaire).

\begin{tabular}{ll}
\hline Name & Description \\
\hline Q1 $\quad$ Choose a reference attribute/ objective. \\
Please select one objective that you are familiar with. If there are two or more objectives that are familiar, just select one. \\
Compare other objectives/ attributes with the reference. \\
Let us assume that the two objectives (one is your chosen reference) are in their worst states. You can now choose one objective \\
that you want to improve to the best-possible state. Or is it equally important to you that both objectives get improved? \\
Ask for strength of preferences. \\
You stated that improving Objective A from its worst to the best-possible case is more important to you than improving Objective B \\
from its worst to the best-possible case. We would like to know how much more important this first improvement is? Please com- \\
plete the _ in by choosing from one of nine categories: An improvement of objective A from the worst to the best case is
\end{tabular}


than (as) an improvement in objective $B$ from the worst to the best case $\left(\mathrm{C}_{1}\right.$ : equally important; $\mathrm{C}_{3}$ : somewhat more important; $\mathrm{C}_{5}$ : more important; $C_{7}$ : much more important; $C_{9}$ : extremely more important; $C_{2}, C_{4}, C_{6}, C_{8}$ : between categories $C_{1}, \ldots, C_{9}$ ).

Weight elicitation was carried out bottom-up in the interview to ease discussing higher-level objectives based on the lower-level attributes. To still avoid the 'splitting bias', we did not show the whole hierarchy when eliciting weights of the five main objectives. At each attribute/ objective level, we presented visualizations (bar charts) of the central weights obtained online (Section 2.5) and asked for confirmation. The respondents could then ask questions, e.g. about attribute ranges, discuss weights, especially if they felt uncertain, and modify answers. If weights were re-assessed, we used the same method on paper. We provided pictures of possible consequences, encouraged open discussion, and allowed stakeholders to change their mind any time.

\subsubsection{Other preference information}

Single-attribute marginal value functions transform the outcomes of alternatives on a single attribute (e.g. CHF/person/year for costs) to a 0-1 value scale. We used the bi-section method to elicit these (Eisenführ et al., 2010). The interviewer emphasized the comparison of attribute improvements to avoid the goal-directed bias (Schuwirth et al., 2012a). The stakeholders were encouraged to respond with an interval instead of a precise number to express vague preferences. Consistency checks were conducted (Eisenführ et al., 2010), and the elicitation was reperformed if necessary. The elicited function could be directly modified by the stakeholders in a graphical representation. Due to time constraints, we only elicited the most important attributes for each stakeholder. For the other attributes, the curvature of the marginal value function (i.e. linear, convex, or concave) was assessed (explained in Scholten et al., 2015).

Due to limited time, We elicited the stakeholders' risk attitudes only for the attributes for which we elicited in detail the marginal value function using the certainty equivalent method (Eisenführ et al., 2010).

In many practical applications, the additive model to aggregate from lower to higher levels of the objectives hierarchy is assumed (e.g. Lienert et al., 2011):

$$
V(x)=\sum_{j=1}^{q} w_{j} v_{j}\left(x_{j}\right)
$$

Where $V(x)$ is the overall value of alternative $x, w_{j}$ is the importance weight of attribute $j, q$ is the number of attributes, $x_{j}$ is the outcome of alternative $x$ on attribute $j$, and $v_{j}\left(x_{j}\right)$ denotes the 
marginal value function of attribute $j$. To use an additive model, several independence conditions have to be fulfilled (Eisenführ et al., 2010). However, these do not always hold, especially in environmental decisions (Langhans and Lienert, 2016). We asked whether the stakeholders agreed with two statements implied by the additive model: (1) Low achievement of some objectives can be fully compensated by high achievement of other objectives; (2) No distinction between a balanced outcome of objectives and more extreme ones with same average value.

In weight elicitation, the attributes/ sub-objectives were only compared with the ones belonging to the same higher-level objectives. A consistency check was performed on the attributes from different higher-level objectives, using the trade-off method (Eisenführ et al., 2010, details see Section SM-3.1.2).

\subsection{Preference modeling}

\subsubsection{Weights}

Let us denote $u$ the uncertainty level ranging from $0 \%$ to $100 \%, r_{j k}$ the most likely ratio between the weight of attribute/ objectives $j\left(w_{j}\right)$ and reference attribute/ objectives $k\left(w_{k}\right)$. If indifference statement in Q2 (see Tab. 4), $r_{j k}=1$; otherwise $r_{j k}=$ strength of preference in Q3 using the 1-to9 conversion scale of AHP (Saaty, 1980). The central weights based on the most likely ratio can be calculated at each level of the objectives hierarchy with $q$ attributes/ objectives:

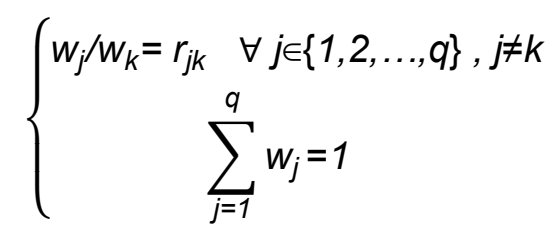

To model the uncertainty of weights, $u$ was interpreted in two ways. We used $r_{j k}\left(r_{j k}\right.$, resp.) to represent the lower (upper, resp.) bound of $r_{j k}$. If the two objectives/ attributes that were compared in Q2 were judged equally important, $u$ indicated the stakeholder's uncertainty about this indifference statement. In this case, $\underline{r_{j k}}=1-8 / 9 u, \overline{r_{j k}}=1+8 u$. When $u=0 \%$, we had $r_{j k}=r_{j k}=\overline{r_{j k}}=1$, which meant that the stakeholder was $100 \%$ sure that the two were indifferent. Another extreme was $u=100 \%$, leading to $r_{j k}=1 / 9$ and $\overline{r_{j k}}=9$, meaning that the stakeholder may hesitate between extremely preferring $j$ to $k$ or vice versa and was completely unsure which one was more important. Otherwise, $u$ indicated his/ her uncertainty about the strength of preferences in Q3. In this case, $r_{j k}=r_{j k}-\left(r_{j k}-1\right) u, \overline{r_{j k}}=r_{j k}+\left(9-r_{j k}\right) u$. If $u=0 \%, r_{j k}=\overline{r_{j k}}=r_{j k}$, which meant that the stakeholder was $100 \%$ sure. If $u=100 \%$, we get $r_{j k}=1, \overline{r_{j k}}=9$. This showed that this stakeholder preferred $j$ to $k$, but was completely unsure about the strength of preference.

\subsubsection{Marginal value functions}

We elicited a few points of the value functions if the bi-section method was used. In this case, 
the value functions were interpolated between the elicited points. If we roughly elicited the shape, we only had minimal information about the value functions. However, it is possible to use standard functional forms as suitable approximation, e.g. exponential or quadratic functions (Keeney and Raiffa, 1976). We assumed exponential functions for non-linear cases:

$$
v_{j}\left(x_{j}\right)= \begin{cases}\left(1-e^{-c_{j} x_{j}^{*}}\right) /\left(1-e^{-c_{j}}\right) & c_{j} \neq 0 \\ x_{j}^{*} & c_{j}=0\end{cases}
$$

where $x_{j}^{*}=\left(x_{j}-x_{j}^{-}\right) /\left(x_{j}^{+}-x_{j}^{-}\right), x_{j}^{-}$and $x_{j}^{+}$are the range of attribute $j$, and $c_{j}$ represents the curvature of the marginal value function.

\subsubsection{Aggregation method}

For those stakeholders who did not agree with additive aggregation, other models such as the multiplicative, multi-linear, worst case, Cobb-Douglas, or a mixed aggregation model might be considered (Keeney and Raiffa, 1976; Langhans et al., 2014). The aggregation method depends on which independence conditions satisfy the stakeholder's preferences. For our case study, additive aggregation was not always suitable because some stakeholders disagreed with the model's assumption of full compensation between objectives. Multiplicative aggregation is commonly suggested in such cases, because it requires weaker preference independence conditions (Keeney and Raiffa, 1976). However, it entails eliciting additional parameters, which has rarely been done in practice (but see e.g. Langhans and Lienert, 2016; Raju and Vasan, 2007). Cobb-Douglas aggregation does not require additional parameters; we chose this due to time limits (Cobb and Douglas, 1928). This model also prefers balanced assessment results to extreme ones with the same arithmetic mean. However, it leads to an aggregated value of zero when any values of sub-objectives are zero (Langhans et al., 2014). We therefore chose a mix of additive and Cobb-Douglas aggregation:

$$
V(x)=\alpha \sum_{j=1}^{q} w_{j} v_{j}\left(x_{j}\right)+(1-\alpha) \prod_{j=1}^{q} v_{j}\left(x_{j}\right)^{w_{j}}
$$

where $\alpha$ represents the proportion of the additive and Cobb-Douglas aggregation and characterizes the uncertainty of aggregation models. The mixed aggregation spans between the extremes of the two models and avoids their undesired properties.

\subsubsection{Converting values to utilities}

Since the predictions of alternatives are uncertain, values need to be converted to utilities. We followed the proposal of Reichert et al. (2015) to elicit marginal value functions at lower-levels of the objectives hierarchy and convert these to utilities at the highest level. The exponential utility function was used: $U(x)=\left(1-e^{-r_{a} V(x)}\right) /\left(1-e^{-r_{a}}\right)$ where $U(x)$ is the utility of alternative $x$, and $r_{a}$ represents the risk attitude (Keeney and Raiffa, 1976). 


\subsection{Choice of robust decision alternatives}

SMAA (Stochastic Multi-criteria Acceptability Analysis) methods have been proposed for discrete MCDA problems, where neither predictions of alternatives nor preference information are precisely known. We applied the SMAA-2 method with Monte Carlo simulation to propagate the uncertainties with random realizations of the uncertain parameters (Lahdelma and Salminen, 2001).

For Monte Carlo simulation, the outcomes of alternatives were sampled independently following their distributions (Section 3.1). Weights were jointly sampled since they were dependent. For weight ratios we assumed a normal distribution, the mean being the most likely ratio (plus standard deviation), and the ratio interval ratio as the $95 \%$ confidence interval. Negative ratio samples were rejected. The weights were calculated from the sampled ratios using equation (2). For marginal value functions, we distinguished detailed elicitation (with bi-section method) and rough elicitation of the approximate shape. For detailed elicitation, the mid-values $x_{0.5}$ (and $\left.x_{0.25}, x_{0.75}\right)$ were elicited as intervals. We assumed a normal distribution, whose $95 \%$ confidence interval was the specified range. Piecewise linear functions were fitted using the sampled values of $x_{0.5}, x_{0.25}$, and $x_{0.75}$. For rough elicitation, the curvature $c_{j}$ was assumed to follow uniform distribution on $[0,10]$ if concave and $[-10,0]$ if convex. The proportion parameter $\alpha$ was assumed to satisfy a uniform distribution on $[0,1]$ for those stakeholders who did not agree with additive aggregation. The uncertainty of the risk attitude was modeled by sampling the curvature $r_{a}$ following a uniform distribution on [-2, 2]. For each setting, we used 10'000 Monte Carlo iterations, which ensured an accuracy of 0.01 for the rank acceptability indices (Tervonen and Lahdelma, 2007).

The descriptive measure of SMAA-2 is the rank acceptability index $b_{i}^{r}$ which measures the frequency of different valuations granting alternative $x_{i}$ ranks $r$ and is best expressed in percent. Note that rank 1 means that the alternative is the best. The holistic rank acceptability index (HRAI) $b_{i}$ of alternative $x_{i}$ can be computed for each alternative as a weighted sum of the rank acceptability index $b_{i}^{r}$ :

$$
b_{i}=\sum_{r=1}^{n} \lambda_{r} b_{i}^{r}
$$

where $\lambda=\left\{\lambda_{1}, \lambda_{2}, \ldots, \lambda_{n}\right\}$ are metaweights and $n$ is the number of alternatives to be ranked. We used inverse weights as metaweights $\left(\lambda_{r}=1 / r\right)$. Such weights emphasized the best ranks and the result was insensitive to the order among the worst ranks.

The analysis was implemented in $\mathrm{R}$ ( $\mathrm{R}$ Core Team, 2014). The R package utility was used to construct the objectives hierarchy and marginal value functions, to convert values to utilities, and to evaluate the alternatives (Reichert et al., 2013). We also used IpSolveAPI package to 
calculate the central weights and sample uncertain weights (Ip_solve and Kjell, 2014).

\subsection{Step-wise local sensitivity analysis procedure}

We addressed (1) how strongly the violation of common assumptions (linear marginal value functions, additive aggregation) influences the results to verify the appropriateness of these assumptions; and (2) which uncertainties matter most to the output uncertainty. We aim at understanding which sources of uncertainty, if reduced, are likely to improve the ability to make informed decisions.

We followed a step-wise approach to evaluate the alternatives under a varying level of uncertainty (Tab. 5). In the settings S1 of the sensitivity analysis, we did not propagate the uncertainty to the ranking. We only varied the preferential parameters of the model. Hereby, changes in the values and rankings are both meaningful (Schuwirth et al., 2012a); we used both. We measured the Euclidean distances between the value vectors of alternatives in the baseline evaluation S11 and in the other settings in S1. To measure the association between rankings, we used Kendall's $t$ correlation coefficient (Kendall, 1938). When the risk attitude was involved (S21, S22, and S4), values were converted to utilities at the highest level of the objectives hierarchy, so only rankings were relevant. Again, we calculated the correlations of the rankings of S21, S22, S3, and S4 with those of S11 using Kendall's $t$ correlation coefficient.

Table 5. Step-wise local sensitivity analysis using different settings. $\mathrm{SH}=$ stakeholder.

\begin{tabular}{ll}
\hline Setting & Definition \\
\hline S1 & No uncertainty propagation \\
S11 & Additive aggregation, deterministic predictions of alternatives, central weights elicited from SH, linear marginal value functions. \\
S12 & As S11, but using the elicited information from SH concerning non-linear shapes of marginal value functions.
\end{tabular}

S131 Aggregation variant 1. As S11, but using Cobb-Douglas aggregation to aggregate the highest-level objectives if additivity assumption was violated, based on discussion with SH. Aggregation of other lower-level objectives remains additive.

S132 Aggregation variant 2. As S11, but a mixed aggregation with $\alpha=0.1$ (10\% additive, $90 \%$ Cobb-Douglas) to aggregate all levels of objectives if additivity assumption was violated, based on discussion with $\mathrm{SH}$.

S133 Aggregation variant 3. As S11, but a mixed aggregation with $\alpha=0.5$ (50\% additive, $50 \%$ Cobb-Douglas) to aggregate all levels of objectives if additivity assumption was violated, based on discussion with $\mathrm{SH}$.

S14 As S11, and including the elicited non-linear shapes of value functions (as S12), mixed aggregation with $\alpha=0.5$ ( $50 \%$ additive, $50 \%$ Cobb-Douglas) to aggregate all levels of objectives (as S133).

S2 Uncertainty of predictions (see Monte Carlo sampling, Section 2.6)

S21 Uncertainties of predictions of alternatives added to S14, assumption of risk neutral SH (i.e. values= utilities; utility function curvature $\left.r_{a}=0\right)$.

S22 Uncertainties of predictions of alternatives added to S14, assumption of risk averse SH (i.e. values transformed to utilities at highest level of objectives hierarchy; utility function curvature $r_{a}=1$ ).

S3 Uncertainty of preferences: Uncertainties of weights, marginal value functions, and aggregation models (sampling $\alpha$ ) added to S14 (see Monte Carlo sampling, Section 2.6; no uncertainty of risk attitude, since predictions are not uncertain).

S4 Uncertainty of preferences and predictions: Uncertainties of risk attitudes, weights, marginal value functions, and aggregation models, and uncertainties of predictions of alternatives added to S14 (see Monte Carlo sampling, Section 2.6). This setting corre- 


\subsection{Communicating results to stakeholders}

A workshop was organized in January 2014 where the decision framework and the results for the case study were presented to an audience of 100 water professionals, including some of the interviewed stakeholders. We gathered feedback concerning the translation of our approach into practical applications.

\section{Results of case study}

\subsection{Predictions of alternatives}

The outcome of each decision alternative was predicted for the 19 attributes, and for each of four future scenarios in 2050 . The uncertainty of predictions is described by probability distributions for each attribute. For reasons of space, we present the complete data and visualization in the SM (Tab. SM-3; Figs. SM-1-8). Some attributes varied significantly across scenarios, such as realization of rehabilitation (attribute 'rehab', see Tab. A.1), percentage of population getting infected ('illn'), pipe collapses and blockages ('failure'), annual cost ('costcap'), and cost increase ('costchange'). Other attributes were very different for alternatives, but similar over scenarios, including flexibility of infrastructure ('adapt'), recovery of phosphate ('phosph'), energy consumption ('econs'), and attributes of social acceptability, e.g. co-determination ('voice'), or time investment by end user ('time'). Some attributes did not differ much over alternatives and scenarios and were subject to large uncertainty, e.g. surface water quality ('chem').

\subsection{Stakeholders' preferences}

\subsubsection{Weights}

We present the weights from the interview. The stakeholders' preferences had large differences, which are shown by the minimum and maximum weights as error bars in Fig. 3a and different distribution of weights for individuals in Fig. 3b). Despite this, there were some common patterns (see Tab. SM-4 for central weights). The two main objectives Safe WW disposal and Protection received the highest weights (Fig. 3a). All stakeholders (SH) except SH1 assigned (central) weights between 0.45 and 0.87 in total to the above-mentioned two main objectives (Fig. 3b). Equity was usually relatively important, with some large differences: $\mathrm{SH} 1$, $\mathrm{SH} 3$, and $\mathrm{SH} 4$ deemed it as the most important objective, while $\mathrm{SH} 6, \mathrm{SH} 7$, and $\mathrm{SH} 9$ regarded it to be the least important. For seven stakeholders, Social acceptance, and for four, Low costs were the least important (Fig. 3b). Consistent with this pattern, the attributes rehabilitation ('rehab', Tab. A.1), surface and ground water quality ('chem', 'exfilsew'), population getting infected ('illn'), and combined sewer overflows ('cso') were on average (central weights averaged over SHs) the top five most important attributes, while all attributes of Social acceptance 
(except 'efqm') and energy consumption ('econs') were the five least important (Tab. SM-4).

The stakeholders used on average $46 \mathrm{mins}( \pm 15)$ to complete the online questionnaire. The interview took 76 mins ( \pm 26 mins) for weight elicitation. Although stakeholders often changed weights or changed the indifference to a preference statement or vice visa, the weights obtained with the two procedures were only rarely negatively correlated $(6.8 \%$, Tab. SM-5).

a

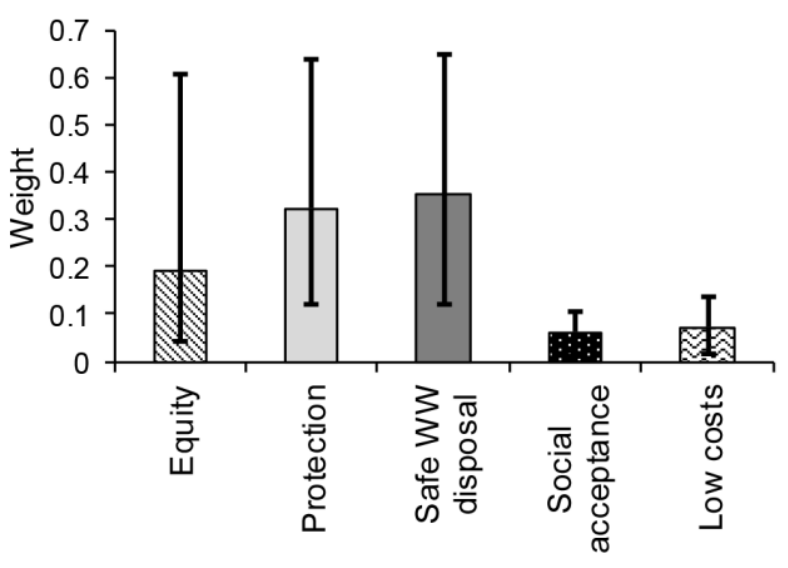

b

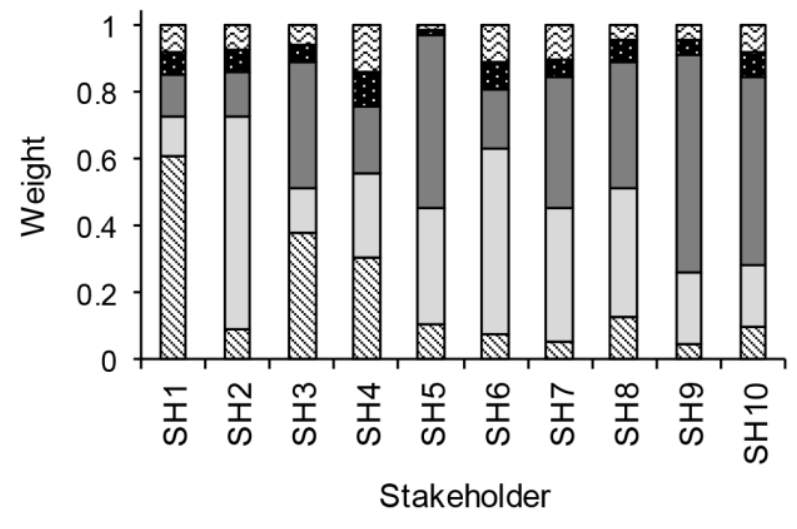

Social acceptance $\mathrm{Q}$ Low costs

Figure 3. Weights given to main objectives. Fig. 3a: central weights averaged over stakeholders (SH) assigned to the highest-level objectives. Note: the error bars are large because they denote the absolute maximum and minimum of central weights given by ten stakeholders. Fig. 3b: central weights assigned by each $\mathrm{SH}$ to the highest-level objectives. Sum of central weights $=1 \mathrm{WW}=$ Wastewater.

\subsubsection{Marginal value functions}

We elicited the 11 most important marginal value functions in detail. One concerns stormwater handling (attribute 'hydr', Tab. A.1), three rehabilitation ('rehab') and CSOs ('cso'), and four population getting infected ('illn'). For other 144 marginal value functions, we roughly elicited the shape. The value functions varied for different stakeholders and attributes (SM, Figs. SM9-24). For surface and ground water quality ('chem', 'exfilsew', 'exfilstruct'), we could use existing value functions (www.modul-stufen-konzept.ch/index; Tab. SM-1). We elicited preference information for 157 of 160 value functions (98\%), of which $123(78 \%)$ were non-linear. For the three value functions without preference information, we assumed linearity. Three stakeholders specified thresholds for attribute levels. These consist of thresholds for 'rehab' by SH1 (Fig. SM-10), 'illn' by SH8 (Fig. SM-14), and 'cso' by SH2 (Fig. SM-15).

\subsubsection{Risk attitude}

In $64 \%$ of the cases, the stakeholders were risk averse, in $27 \%$ risk prone, and in $9 \%(=1 \mathrm{SH})$ risk neutral (Tab. SM-6). 


\subsubsection{Trade-off questions and aggregation models}

Inconsistencies occurred four times that were all resolved by re-eliciting weights of the five main objectives. Incomparability happened to $\mathrm{SH} 2$ and $\mathrm{SH} 4$. For instance, it was impossible for SH2 to trade surface water quality ('chem') with rehabilitation ('rehab'), as 'chem' was far more important. Note that outranking methods allow incomparability of alternatives but are beyond the scope of this paper (e.g. Figueira et al., 2013). The remaining trade-off questions indicated consistency.

Additive aggregation was satisfactory only for $\mathrm{SH} 1, \mathrm{SH}$, and $\mathrm{SH} 10$. The others either stated that the compensatory effect could be represented by the assigned weights, or not achieving $100 \%$ of all objectives, i.e. compensation, was acceptable. For the other stakeholders, mixed aggregation was more suitable. Most agreed to compensate their less important objectives to improve important ones, but the opposite direction was not applicable.

\subsection{Choice of robust alternatives (all uncertainties)}

Some alternatives performed very similarly, irrespective of preferences, since they had similar configurations (A1a vs. A1b; A4 vs. A5; A8c vs. A8d; Figs. SM-1-8). We show results without $A 1 b, A 5$, and $A 8 c$. Despite high uncertainty in the ranking, it was possible to identify robust alternatives using rank acceptability indices with visualization; exemplified for stakeholder $\mathrm{SH} 1$. Alternative A1a (top row, Fig. 4) received the lowest rank of 10 with a low probability of 0.07 (striped bar), while alternative A9 (bottom row) had a high probability of 0.46 to receive this lowest rank 10. Alternative A8a (seventh row) had a high probability of 1 to receive a very good ranking, i.e. always rank 4 (black white polka-dotted bar) or better, but only a probability of 0.07 to be ranked first (small black bar). Alternative A8b had a higher probability of 0.75 to rank first (large black bar). Thus, SH1 may choose A8b because it ranked first with highest probability. However, the choice seemed less clear for some stakeholders (Figs. SM-25-34). Here, holistic rank acceptability indices (HRAl) can be calculated to derive a ranking (Fig. 5). 


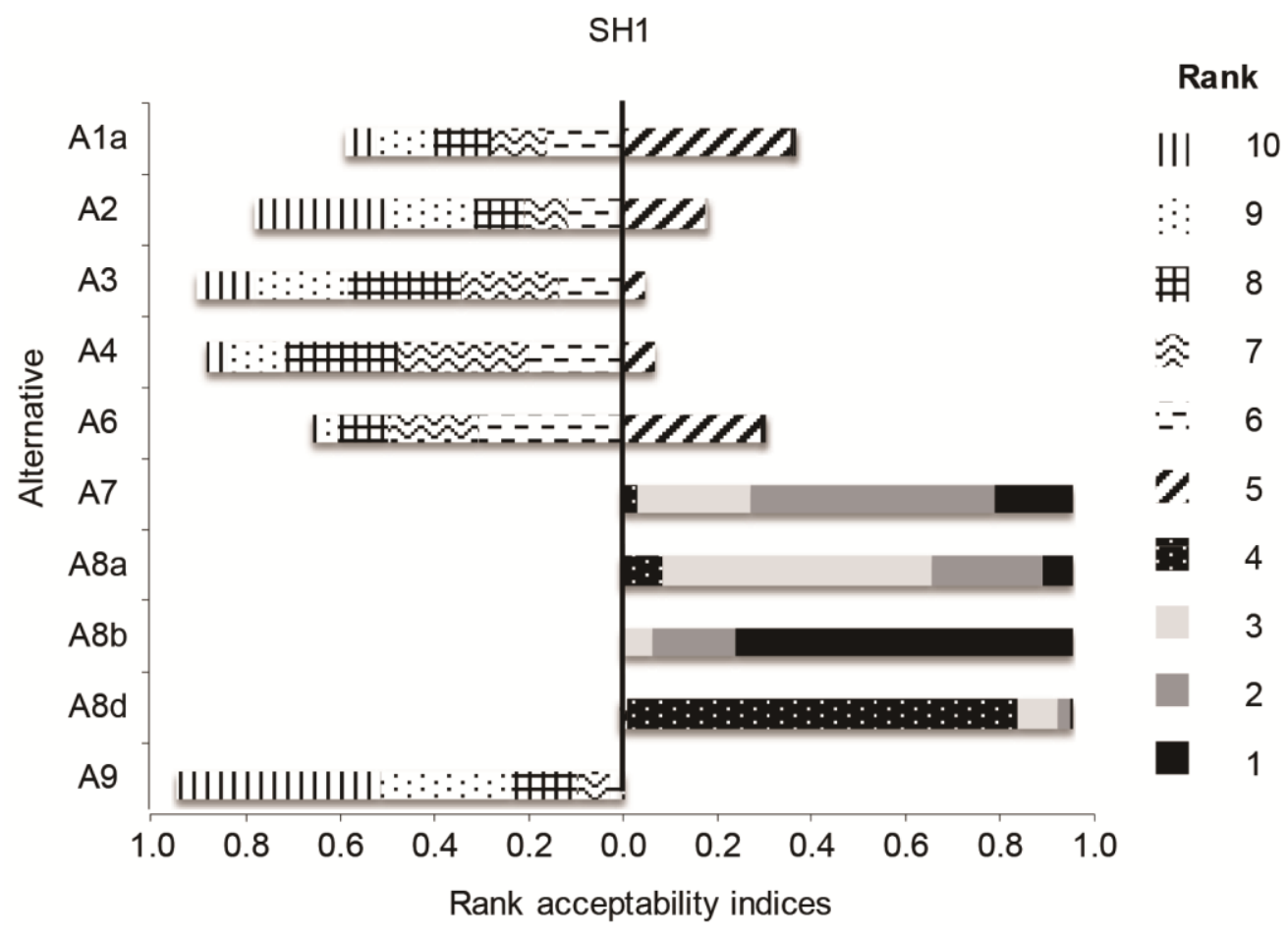

Figure 4. Rank acceptability indices including all sources of uncertainty (sensitivity analysis setting S4) for stakeholder $\mathrm{SH} 1$ in Status Quo scenario. y-axis= alternatives A1a-A9; $x$-axis= rank acceptability indices (stacked bars $=$ uncertainty of respective rank). Legend= ranks. Rank acceptability index $b_{i}^{r}=$ probability that alternative $x_{i}$ ranks $r$. To the right of the bold vertical line we show $b_{i}^{r}$ when $r \leq 5$, i.e. probability between $[0,1]$ that the respective alternative is ranked 5 or better. Left of bold vertical line $(r \geq 6)$ are the probabilities that the alternative receives a poor ranking (i.e. rank 6 or worse).

For all stakeholders, the Qualitative Growth and Doom scenarios produced similar results as the Status Quo, so only the latter and Boom are presented (Fig. 5). In the Status Quo scenario, the Status Quo alternatives A8a (with storm water retention; Tab. 3) and A8d (with super central wastewater treatment) performed fairly well for all stakeholders, always belonging to the top four alternatives (Fig. 5, left). However, the Status Quo can be improved by alternative A7 (fully decentralized with on-site treatment). It performed best for stakeholders $\mathrm{SH} 2, \mathrm{SH} 4, \mathrm{SH}$, $\mathrm{SH} 7$, and $\mathrm{SH} 8$, and second best for $\mathrm{SH} 1, \mathrm{SH}$, and $\mathrm{SH} 5$. Alternative A8b (decentralized wastewater treatment) achieved controversial results. It was best for $\mathrm{SH} 1$ and $\mathrm{SH} 5$, second best for $\mathrm{SH} 2$, but had a high chance to rank worse than five for SH6-SH10 (Fig. 5 left; Figs. SM-30-34). The other alternatives only performed moderately (A1a, A2, A6) or badly (A3, A4, A9). Further explanations are given in the SM (Section SM-4.1). 

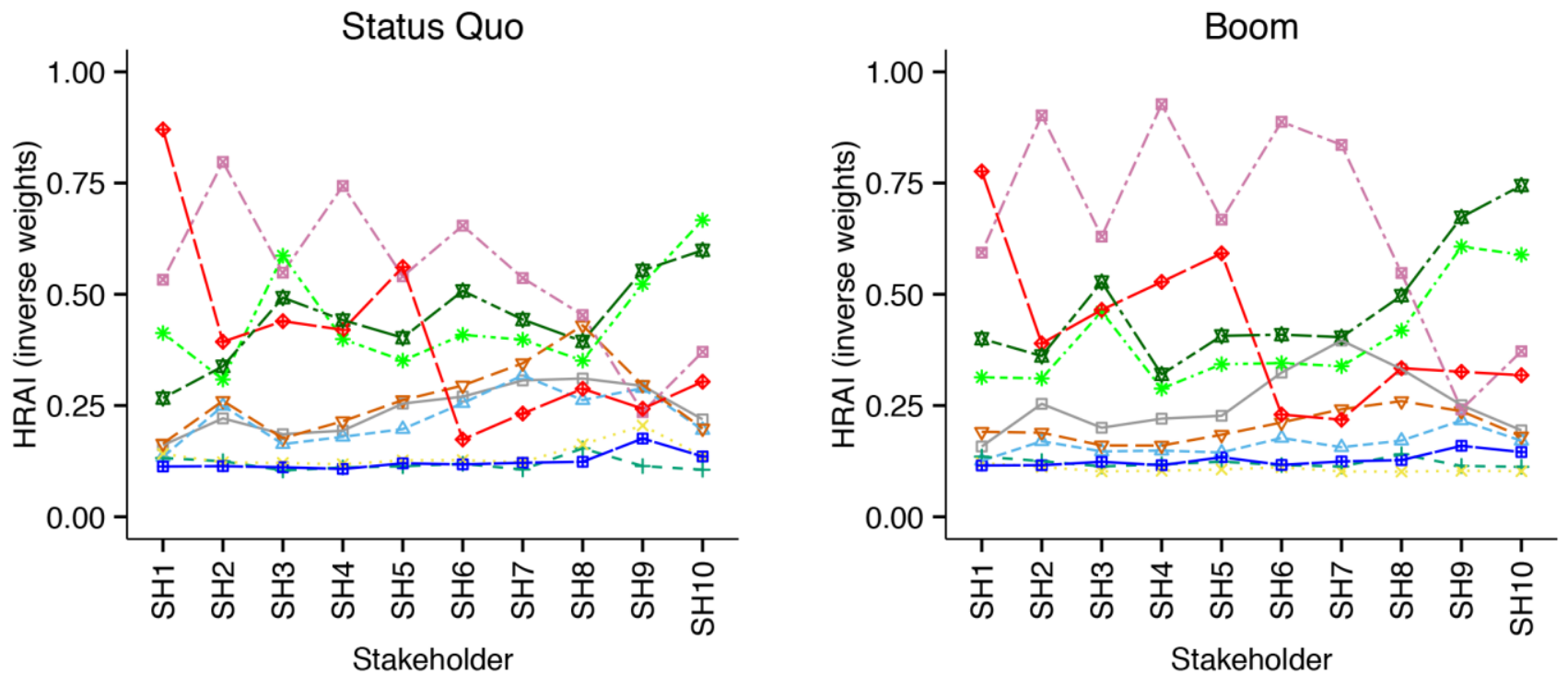

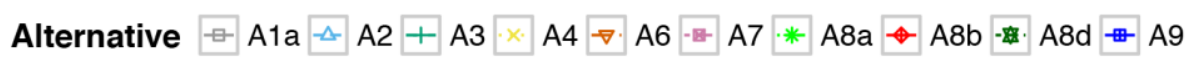

Figure 5. Holistic rank acceptability indices (HRAl; y-axis) of alternatives (A1a-A9) for all stakeholders (SH1-SH10; $\mathrm{x}$-axis) in the Status Quo and Boom scenarios including all uncertainties (sensitivity analysis setting S4). Rank acceptability index $b_{i}^{r}$ is the probability that alternative $x_{i}$ ranks $r$; it is weighted by $1 / r$ (inverse weights) and aggregated to obtain the HRAI.

The Boom scenario had a strong influence. Notably, alternative A7 performed better in the Boom scenario for all stakeholders (Fig. 5, right) than in the Status Quo, while A6 performed worse for nine (except SH1). This can be explained by the worse performance of some alternatives on attributes such as rehabilitation ('rehab', Tab. A.1), stormwater handling ('hydr'), population getting infected ('illn'), and costs ('costcap') in the Boom scenario (Figs. SM-1-8). The rehabilitation strategy of A6 implied that only a very low fraction of the rehabilitation demand was realized in the Boom scenario where the sewer network was massively expanded (poor performance on 'rehab', Fig. SM-1). Because of the high influence of 'rehab' (discussed in Section SM-4.1), A6 accordingly ranked lower. Note that stakeholder feedback about the elicitation procedure and MCDA decision framework is given in the supplementary material (Section SM3.4-3.5).

\section{Step-wise sensitivity analysis}

\subsection{Violation of common assumptions (S1)}

For setting S1, we present results for ten stakeholders and only the Status Quo scenario. This sufficiently illustrates how the violation of assumptions can affect results (values see Fig. 6; rankings see supplementary material, Figs. SM-35). Setting S11 implemented common assumptions, i.e. additive aggregation, linear marginal value functions, and did not propagate uncertainties. We analyzed how the results in other settings of $\mathrm{S} 1$ deviate from these (Table 6; 
individual results for each stakeholder see Tabs. SM-10-11).

Table 6. Sensitivity analysis. Comparing results of setting S11 (common simplifications; Tab. 5) with the other settings (Tab. 5) in the Status Quo scenario. Distance= Euclidean distances between value vectors from the other settings and those in S11; Kendall's $\tau=$ Kendall's $\tau$ rank correlation coefficient between ranking from other settings and those in S11. Aver= average values of all stakeholders; SD= standard deviation. For settings S2, S3, and S4, only Kendall's $\mathrm{t}$ is calculated; Aver= average values (over samples) of Kendall's $\tau$ for all stakeholders; $S D=$ average values of standard deviation of Kendall's $T$ (all samples). $\mathrm{VF}=$ marginal value functions; $\mathrm{OH}=$ objectives hierarchy; unc= uncertainty.

\begin{tabular}{|c|c|c|c|c|c|c|c|c|c|c|}
\hline & \multicolumn{2}{|l|}{ S12 } & \multicolumn{2}{|l|}{ S131 } & \multicolumn{2}{|c|}{ S132 } & \multicolumn{2}{|l|}{ S133 } & \multicolumn{2}{|l|}{ S14 } \\
\hline & Aver. & SD & Aver. & SD & Aver. & SD & Aver. & SD & Aver. & SD \\
\hline Distance & 0.17 & 0.15 & 0.09 & 0.08 & 0.34 & 0.25 & 0.13 & 0.10 & 0.21 & 0.17 \\
\hline \multirow[t]{3}{*}{ Kendall's $T$} & 0.88 & 0.11 & 0.95 & 0.06 & 0.82 & 0.20 & 0.88 & 0.15 & 0.83 & 0.15 \\
\hline & \multicolumn{2}{|l|}{ S21 } & \multicolumn{2}{|l|}{ S22 } & \multicolumn{2}{|l|}{ S3 } & \multicolumn{2}{|l|}{ S4 } & & \\
\hline & Aver. & SD & Aver. & $\mathrm{SD}$ & Aver. & SD & Aver. & $\mathrm{SD}$ & & \\
\hline Kendall's $T$ & 0.65 & 0.13 & 0.65 & 0.13 & 0.79 & 0.07 & 0.52 & 0.15 & & \\
\hline
\end{tabular}

$\mathbf{S 1 2}$ (non-linear value functions): Compared to setting S11, the values of alternatives were considerably influenced in S12 by replacing linear with non-linear marginal value functions (Euclidean distance=0.17 averaged over SH; Tab. 6; individual SH results: Tab. SM-10). Thresholds also had a significant impact. For instance, the values of alternatives A1a, A2, and A6 decreased dramatically (>0.28) for $\mathrm{SH} 1$ because of the threshold for 'rehab', considerably changing the ranking (Kendall's $r=0.69$; Tab. SM-10). However, for most stakeholders, the ranking was only marginally affected (Kendall's $t=0.88$ averaged over $\mathrm{SH}$; Tab. 6).

S131, S132, and S133 (aggregation variants): Compared to S11, the values of alternatives decreased in all three settings for the stakeholders who did not agree with additive aggregation (SH2, SH4-9; Fig. 6). This is because Cobb-Douglas aggregation evaluates balanced value combinations better than extreme ones with the same value (Langhans et al., 2014). So compared with $S 11$, a higher proportion of Cobb-Douglas aggregation in $S 132(\alpha=0.1: 10 \%$ additive aggregation, 90\% Cobb-Douglas for all levels of objectives) resulted in larger value differences than in $S 133(\alpha=0.5)$. The value differences between $S 11$ and $S 131$ (main objectives: all CobbDouglas; lower levels: additive) were the smallest. However, the influence on the ranking of alternatives was not significant (Kendall's $\mathrm{T}>0.8$ in S131, S132, and S133, averaged over stakeholders; Tab. 6), but some special cases exist. For instance, the sixth ranked alternative 

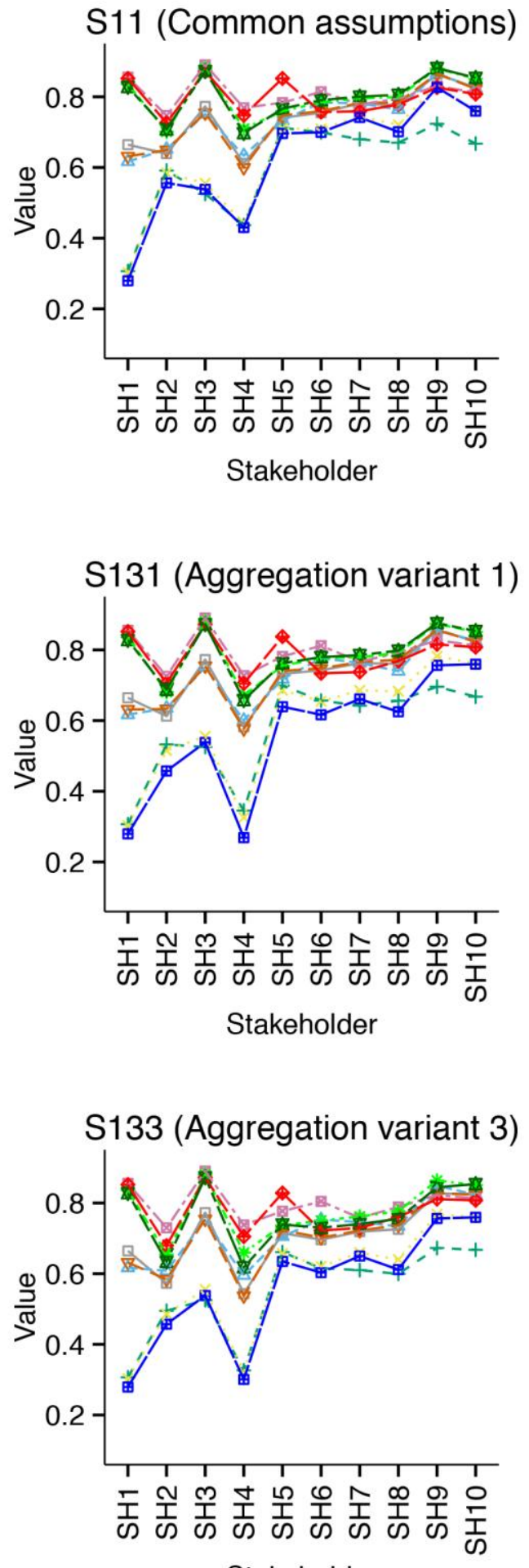
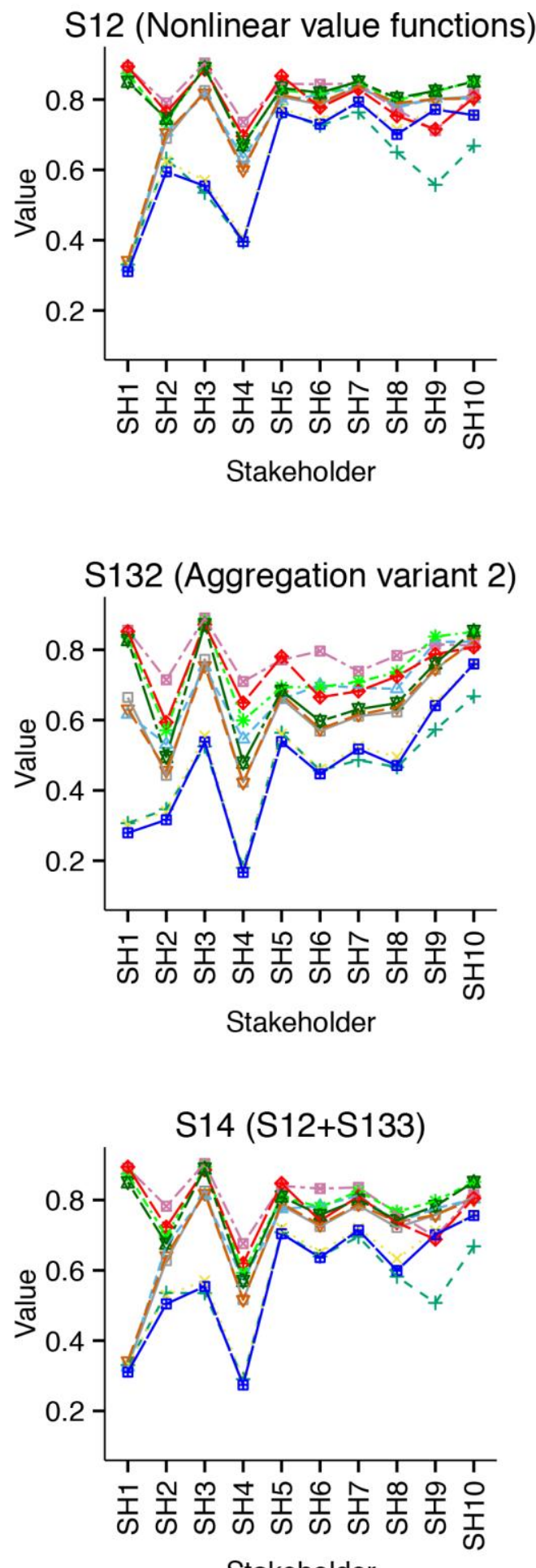

Stakeholder

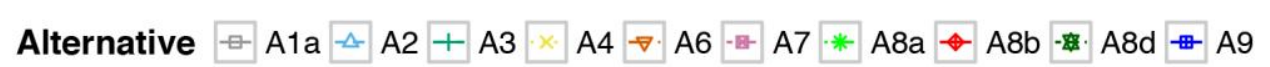

Figure 6. Values of selected alternatives (A1a-A9) in the sensitivity analysis variants of setting $S 1$ (no uncertainty, see Tab. 5) for all ten stakeholders ( $\mathrm{SH}$; x-axis) and the Status Quo scenario. The values (yaxis) between $[0,1]$ denote how well the objectives are achieved: value of $0=$ none of the objectives are reached; $1=$ all are fully achieved. 
A7 in $\mathrm{S} 11$ became the best in S132 for SH7 (Fig. SM-35).

S14 (non-linear value functions and mixed aggregation for all levels of objectives): This setting combined the two effects of S12 (non-linear value functions) and S133 (mixed aggregation; Tab. 5). Similarly as above, the high distance of value vectors of alternatives (distance $=0.21$ averaged over SHs; Tab. 6 ) did not necessarily lead to rank reversals (Kendall's $\tau=0.83$ averaged over SHs; Tab. 6), but not for all SHs (Tab. SM-10).

\subsection{Step-wise uncertainty analysis}

To analyze uncertainty, average Kendall's $\tau$ describes the deviation of the uncertain rankings from the baseline setting S11, and the relative standard deviation of Kendall's $r$ the uncertainty level of the ranking. First, the risk attitude had no effect on the ranking; see the results of S21 (risk neutrality) and S22 (risk aversion; Tab. 6). Second, the rankings in settings S2 and S4 generally diverged considerably from S11 (Kendall's $t=0.67$ and 0.52; Tab. 6). The high standard deviation of Kendall's $\tau$ of 0.13 in S2 (only uncertainty of predictions, but precise preferences) suggested a substantial contribution of the prediction uncertainty to the uncertainty of ranking. Indeed, the standard deviation increased only slightly to 0.15 when all other uncertainties were included in setting S4. This was valid for all stakeholders, despite that the influence of different uncertainty components depended on a particular stakeholder (Tab. SM-11). We present the influence of uncertainty of each individual preference parameter (weights, marginal value functions, aggregation model, risk attitude) only in the SM (Table SM-11).

\section{Discussion}

\subsection{Results of the case study}

Given the ranges of the best and worst cases for the case study, the main objectives Safe WW disposal and Protection received the highest weights. This is reasonable as they are the main professional purposes of wastewater infrastructure. However, it is surprising that Low costs was perceived as rather unimportant by all stakeholders (Fig. 3). This pattern is consistent with two independent studies of SWIP using a similar objectives hierarchy (Lienert et al., 2016; Scholten et al., 2015). These findings are also in line with other surveys, which generally indicate high environmentally-friendly behavior of Swiss people (Kaiser and Wilson, 2000), also specifically in the water sector (Logar et al., 2014). However, in our earlier stakeholder analysis with open interview questions, we found that the stakeholders were strongly concerned about economic interests, followed by technical issues (Lienert et al., 2013). This indicates the importance of eliciting the underlying values through the cognitively demanding trade-off judgments. Although time-intensive, it is beneficial if stakeholders can construct their preferences when thinking about difficult choices (Gregory et al., 2012). Our observation also underpins the importance of considering case-specific data and emphasizing ranges when 
eliciting preferences, rather than asking for general 'importance weights'.

Despite the average preference pattern being consistent with other studies, the individual preferences differed relatively strongly between stakeholders. This is especially relevant for the most important three main objectives, Equity, Safe WW disposal, and Protection (see the wide ranges of weights for the three in Fig. 3a). However, we wish to point out that the error bars for "Social acceptance" and "Low costs" are much narrower. There seems to be a difference between these two objectives and the other three, which would likely be statistically significant if a larger sample size were available (also see Langhans and Lienert, 2016). The stakeholders are from different decisional levels, and have different professional roles and personal backgrounds, which influences their preferences. For instance, stakeholder SH1 gave a high weight of 0.61 to the main objective Equity. As WWTP engineer, he believed that realizing the rehabilitation demand is the basis of achieving other objectives. He also explicitly stated that as a father he did not want burden the next generation with rehabilitation. However, the purpose of our preference elicitation was not to investigate the reason for their preferences. Rather, we focused on helping the stakeholders to formulate their preferences for the MCDA. Our related study shows that the SMART/SWING-variant for weight elicitation leads to a larger spread of weights than SWING (Lienert et al., 2016). The wide ranges of weights can also partially be attributed to this effect. We also wish to emphasize that we selected specifically these stakeholders because we wanted to account for different perspectives in the decision.

Surprisingly, a very unconventional alternative A7 (fully decentralized with high-tech on-site treatment; Tab. 3) performed robustly best for most stakeholders in all scenarios (Fig. 5). Reasons are a good performance on rehabilitation (low burden to the next generation), flexibility (quick response to changes), efficient pollutant removal, and nutrient recycling (recovery of phosphate from urine). Exceptions are stakeholders $\mathrm{SH} 9$ and $\mathrm{SH} 10$, who were concerned about the risk of infections, which is higher in decentralized systems due to maintenance by end users. We conclude that there is high potential for decentralized technologies even in an industrialized country as Switzerland. Indeed, engineers are increasingly exploring decentralized technologies for sustainability reasons and because it increases flexibility (Guest et al., 2009; Larsen et al., 2009; Larsen et al., 2016). Specifically, for urine source separation, a review showed high acceptance among European users (Lienert and Larsen, 2010). For a more detailed discussion about these alternatives, see Section SM-4.1.

\subsection{Simplified preference elicitation}

Our preference elicitation clearly indicated that the common linearity assumption of marginal value functions did not hold (as Langhans and Lienert, 2016). Non-linear marginal value functions using sensitivity analysis setting $S 12$ (Tab. 5) could considerably change the values of alternatives (Fig. 6). However, the ranking was quite stable (Tab. 6), except if the values of 
alternatives were close (e.g. for SH10; Fig. 6), or if there were acceptance thresholds (e.g. 70\% 'rehab' for SH1; Fig. SM-10). This finding is in line with Lahdelma and Salminen (2012). Detailed elicitation of the marginal value function using the bi-section method took 19 mins. $( \pm 6$ mins.) per attribute. Obviously, rough elicitation was more time-efficient ( $<1 \mathrm{~min}$.) and also easier for stakeholders (see feedback; Tab. SM-9). Therefore, we recommend verifying the linearity assumption of marginal value functions by rough elicitation and asking for potential thresholds. Detailed elicitation should only follow if the sensitivity analysis shows that this is crucial to distinguish alternatives.

Additive aggregation is widely used because of its simplicity (Eisenführ et al., 2010). However, seven of ten stakeholders thought that their preferences could not be represented by this model. Moreover, the sensitivity analysis of settings S131, S132, and S133 (Tab. 5) showed that aggregation models could significantly impact the resulting values of alternatives (Tab. 6; Fig. 6). Again, however, the ranking was only slightly influenced in most (but not all) cases. Considering the difficulty of identifying a more expressive, but complicated aggregation model, it might be reasonable to nevertheless use the additive assumption and check for its sensitivity later, as demonstrated here.

With predicting uncertainty, the stakeholder's risk attitude should be included to convert values to utilities. However, the ranking was insensitive to the risk attitude, as sensitivity analysis setting S22 assuming risk aversion and S21 assuming risk neutrality led to identical results (Tab. 6; Tab. SM-11). Therefore, the risk attitude should only be elicited if the sensitivity analysis indicates that this is decisive. Nevertheless, we find it interesting that in most cases, the stakeholders were risk averse (64\%) or risk prone (27\%), and in only $9 \%$ risk neutral (Tab. SM-6).

\subsection{Considering uncertainty}

Our framework incorporates various sources of uncertainty. The external socio-economic uncertainty was captured by scenarios. As others (Karvetski et al., 2011; Ram and Montibeller, 2013; Scholten et al., 2015), we find combining MCDA with scenarios beneficial. In our case, some rankings of alternatives were sensitive especially to the massive-growth Boom scenario (Fig. 5). Scenarios thus give valuable information on the robustness of alternatives and their response to changing external environments.

When predicting long-term outcomes of alternatives, uncertainties are unavoidable (Reichert et al., 2015); we explicitly modeled these with probability distributions. The sensitivity analysis showed that the prediction uncertainty is crucial, since the rankings deviated clearly from the baseline setting without uncertainty (Tab. 6). Moreover, prediction uncertainty contributed substantially to the output uncertainty (Tab. 6; Tab. SM-11). Indeed, some evaluation results were so uncertain that they covered nearly the entire possible range, although great efforts were invested to predict the performance of alternatives. For example, to predict surface water quali- 
ty (attribute 'chem'; Fig. SM-2), wastewater discharge had to be translated into our indicator until 2050, despite many sources of uncertainty such as precipitation, climate models, and treatment efficiency of pollutants. Another example is the prediction of the population getting infected because of contact with wastewater ('illn'; Fig. SM-5). Here, quantification involved intermediate steps about cause-effect relationships between the quantity of a certain pathogen and the infection risk, which are highly uncertain. For other attributes we interviewed experts (e.g. flexibility of infrastructure, 'adapt'), or carried out extensive literature reviews (e.g. time investment by end user, 'time'). Here, uncertainty arises from diverse opinions or different sources.

Where possible, we used 'natural' attributes that addressed the decision concerns directly, such as 'illn'. Choosing more 'factual' and proxy attributes, e.g. the concentration of pollutants, might simplify the predictions and reduce uncertainty. However, stakeholders might lack the knowledge to make value judgments because factual attributes do not per se address their concern. Beinat (1997) showed that measurability, controllability, and neutrality are reasons why factual attributes are more frequently used in practice. In our case, for some stakeholders the alternatives achieved rather close Holistic Rank Acceptability Indices (HRAl; Fig. 5). This indicates high uncertainty of the ranking, which might hinder decision-making. In such situations, more effort is needed to reduce the uncertainty of predictions, if possible by choosing different attributes.

\section{Conclusions}

Our work provides a novel perspective for wastewater infrastructure planning using a scenariobased MCDA framework. Our focus was to incorporate the preferences of stakeholders in MAUT, taking into account various sources of uncertainties. We also propose a step-wise local sensitivity analysis that can easily be applied by practitioners. Applying the proposed decision framework to the case study, we find:

(1) The difficult trade-off questions helped stakeholders to construct their preferences and reveal their underlying values. It is misleading to judge the intrinsic importance of objectives without trade-offs and case-specific ranges.

(2) The SMAA-analysis provides a practical way to identify robust alternatives with uncertain evaluation results. The good performance of the unconventional fully decentralized, high-tech alternative $A 7$ using urine source separation for wastewater handling in the case study is a positive indication that novel wastewater systems could indeed be viable (as proposed e.g. in Larsen et al., 2009). These increase sustainability in urban water management by recycling nutrients as the limited resource phosphorus, while reducing eutrophication and the load of micro- and other pollutants in water bodies.

(3) Combining scenario planning and MCDA is beneficial to wastewater infrastructure planning, 
as the performance of alternatives proves sensitive to future boundary conditions.

(4) Elicitation reveals that common simplifying assumptions (linear marginal value functions, additive aggregation model) do not always hold (as Langhans and Lienert, 2016). The sensitivity analysis clearly shows that these assumptions need to be tested in each case. Thus, the sensitivity analysis can help to elicit preferences for MAUT more effectively, and with less input from stakeholders, because some parameters (e.g. marginal value functions, risk attitude, aggregation model) are only needed when they have important effects on the ranking.

(5) The sensitivity analysis shows that including prediction uncertainty is crucial in our application because the resulting ranking was considerably different from the baseline setting without uncertainty. Future effort should thus aim at reducing uncertainty in attribute predictions.

There should be a shift of the engineering planning paradigm to include stakeholders, uncertainties, and multi-criteria sustainability indicators. However, many practitioners that gave feedback to our scenario-based MCDA framework stated that there was a gap between our theoretic approach and practical implementation, as also reported in other wastewater infrastructure management studies (Cardoso et al., 2012; Hurley et al., 2008). This might indicate that complexity and investment could be an important reason why MCDA has not been so commonly used in this area (Kiker et al., 2005). We recommend devoting future work to improve the practicability of the framework to support this paradigm change.

\section{Acknowledgements}

This work resulted from National Research Program 'Sustainable Water Management' (NRP 61; Project No. 406140_125901/1) was supported by the Swiss National Science Foundation. We further thank Jonas Maria Eppler, Cristina Fritzsche, Mark Honti, Max Maurer, Peter Reichert, Lisa Scholten, Nele Schuwirth, and Anja Zorn for their valuable contributions. We especially thank the stakeholders from the case study for their participation.

\section{Appendix}

Table A.1. List of abbreviations. A. used in the water sector, in decision analysis, and some other abbreviations; B. short names and definitions of the objectives; bold= main objectives.

\begin{tabular}{ll}
\hline A. Abbreviation & Description \\
\hline AHP & Analytic hierarchy process \\
Aver & Average \\
CSO & Combined sewer overflow \\
ELECTRE & ELimination and Choice Expressing the REality \\
exfil & exfiltration \\
GAIA & Geometrical analysis for interactive assistance \\
HRAI & Holistic rank acceptability index \\
IKA & Intercommunal agency (several communities that manage the water infrastructure together)
\end{tabular}




\begin{tabular}{|c|c|}
\hline MAUT & Multi-attribute utility theory \\
\hline MAVT & Multi-attribute value theory \\
\hline MCDA & Multi-criteria decision analysis \\
\hline NRP & National research programme of the Swiss national science foundation \\
\hline $\mathrm{OH}$ & Objectives hierarchy \\
\hline PROMETHEE & Preference Ranking OrganisationMETHod for Enrichment Evaluations \\
\hline SD & Standard deviation \\
\hline SM & Supplementary material \\
\hline SH & Stakeholder \\
\hline SMAA & Stochastic multi-criteria acceptability analysis \\
\hline SMART/SWING & Method to elicit weights \\
\hline SWING & Method to elicit weights \\
\hline SWIP & Project: Sustainable water infrastructure planning \\
\hline unc & Uncertainty \\
\hline VF & Value function \\
\hline WW & Wastewater \\
\hline WWI & Wastewater infrastructure \\
\hline WWTP & Wastewater treatment plant \\
\hline B. Short name & Objective \\
\hline adapt & Flexible system adaptation \\
\hline area & Low additional area demand for end user \\
\hline chem & Good chemical state of watercourses \\
\hline collab & Low unnecessary construction and road works \\
\hline costcap & Low annual costs \\
\hline costchange & Low cost increase \\
\hline cso & Few gastro-intestinal infections through indirect contact with wastewater (swimming after CSOs) \\
\hline Equitya & Intergenerational equity \\
\hline econs & Efficient use of electrical energy \\
\hline efqm & High quality of management and operations; assessment framework for measuring improvements of an organization \\
\hline exfiltrsew & Low contamination from sewers (through exfiltration, i.e. damaged sewers) \\
\hline exfiltrstruct & Low contamination from infiltration structures \\
\hline failure & Few structural failures of drainage system \\
\hline hydr & Low negative hydraulic impacts \\
\hline illn & Few gastrointestinal infections through direct contact with wastewater (infrastructure failures) \\
\hline phosph & Nutrient recovery using the indicator phosphate recovery \\
\hline Protection ${ }^{a}$ & Protection of water and other resources \\
\hline rehab & Low future rehabilitation burden until 2050 \\
\hline $\begin{array}{l}\text { Safe WW dis- } \\
\text { posala }\end{array}$ & Safe wastewater disposal \\
\hline service & Sufficient drainage capacity of drainage system \\
\hline time & Low time demand for end user \\
\hline voice & High co-determination of citizens in infrastructure decisions \\
\hline
\end{tabular}

\footnotetext{
a The highest level main objectives.
} 


\section{Supplementary material}

Supplementary material for this article containing details of objectives and attributes, alternatives, preference elicitation procedure and results, and MCDA results can be found in the online version of this paper at $\mathrm{xxx}$

\section{References}

Ashley, R., Blackwood, D., Butler, D., Jowitt, P., Davies, J., Smith, H., Gilmour, D., OlteanDumbrava, C., 2008. Making asset investment decisions for wastewater systems that include sustainability. J. Environ. Eng. 134, 200-209. DOI:10.1061/(Asce)0733-9372(2008)134:3(200) AWEL, 2006. „Amt für Abfall, Wasser, Energie und Luft, Kt. Zürich" (Office for waste, water, energie, and air, ct. Zürich). „Zustand der Fliessgewässer in den Einzugsgebieten von Glatt und Greifensee - Messkampagne 2004/ 2005" in German (State of watercourses in the catchments of Glatt and Greifensee - measurement campagne 2004/2005).

Behzadian, M., Kazemzadeh, R.B., Albadvi, A., Aghdasi, M., 2010. PROMETHEE: A comprehensive literature review on methodologies and applications. Eur. J. Oper. Res. 200, 198-215. DOI:10.1016/j.ejor.2009.01.021

Beinat, E., 1997. Value functions for environmental management. Springer.

Belton, V., Stewart, T., 2002. Multiple Criteria Decision Analysis: An Integrated Approach. Kluwer Academic Publishers, Dordrecht, The Netherlands.

Bernard, R., Denis, B., 1993. Aide Multicritère à la Décision: méthodes et Cas. Economica. Brans, J.P., Vincke, P., Mareschal, B., 1986. How to select and how to rank projects: the Prométhée method. Eur. J. Oper. Res. 24, 228-238. DOI:10.1016/0377-2217(86)90044-5 Cardoso, M., Silva, M.S., Coelho, S., Almeida, M., Covas, D., 2012. Urban water infrastructure asset management-A structured approach in four water utilities. Water Sci. Technol. 66, 27022711. DOI:10.2166/wst.2012.509

Chung, E.S., Lee, K.S., 2009. Prioritization of water management for sustainability using hydrologic simulation model and multicriteria decision making techniques. J. Environ. Manage. 90, 1502-1511. DOI:10.1016/j.jenvman.2008.10.008

Cinelli, M., Coles, S.R., Kirwan, K., 2014. Analysis of the potentials of multi criteria decision analysis methods to conduct sustainability assessment. Ecol. Indic. 46, 138-148.

DOI:10.1016/j.ecolind.2014.06.011

Cobb, C.W., Douglas, P.H., 1928. A theory of production. Am Econ Rev, 139-165.

Dominguez, D., Truffer, B., Gujer, W., 2011. Tackling uncertainties in infrastructure sectors through strategic planning: the contribution of discursive approaches in the urban water sector. Water Policy 13, 299. DOI:10.2166/wp.2010.109

Dyer, J.S., 1990. Remarks on the analytic hierarchy process. Manage. Sci. 36, 249-258.

DOI:10.1287/mnsc.36.3.249

Dyer, J.S., 2005. Maut-Multiattribute Utility Theory, in: Figueira, J., Greco, S., Ehrogott, M. (Eds.), Multiple Criteria Decision Analysis: State of the Art Surveys. Springer New York, New York, pp. 265-292.

EEA, 2012. European Environment Agency. European waters-current status and future challenges - a synthesis.

Egger, C., Maurer, M., 2015. Importance of anthropogenic climate impact, sampling error and urban development in sewer system design. Water Res. 73, 78-97.

DOI:10.1016/j.watres.2014.12.050

Egger, C., Scheidegger, A., Reichert, P., Maurer, M., 2013. Sewer deterioration modeling with condition data lacking historical records. Water Res. 47, 6762-6779.

DOI:10.1016/j.watres.2013.09.010

Eisenführ, F., Martin, W., Thomas, L., 2010. Rational Decision Making, 1st ed. Springer Verlag, Berlin, Heidelberg, New York.

Figueira, J.R., Greco, S., Roy, B., Słowiński, R., 2013. An Overview of ELECTRE Methods and their Recent Extensions. J. Multi. Crit. Decis. Anal. 20, 61-85. DOI:10.1002/mcda.1482

Goodwin, P., Wright, G., 2001. Enhancing strategy evaluation in scenario planning: a role for 
decision analysis. J. Manage. Stud. 38, 1-16. DOI:10.1111/1467-6486.00225

Greco, S., Matarazzo, B., Slowinski, R., 2001. Rough sets theory for multicriteria decision analysis. Eur. J. Oper. Res. 129, 1-47. DOI:Rough sets theory for multicriteria decision analysis Gregory, R., Failing, L., Harstone, M., Long, G., McDaniels, T., Ohlson, D., 2012. Structured decision making: a practical guide to environmental management choices. John Wiley \& Sons. Guest, J.S., Skerlos, S.J., Barnard, J.L., Beck, M.B., Daigger, G.T., Hilger, H., Jackson, S.J., Karvazy, K., Kelly, L., Macpherson, L., 2009. A new planning and design paradigm to achieve sustainable resource recovery from wastewater. Environ. Sci. Technol. 43, 6126-6130. DOI:10.1021/es9010515

Hajkowicz, S., Collins, K., 2007. A review of multiple criteria analysis for water resource planning and management. Water Resour. Manag. 21, 1553-1566.

Howard, R.A., 1988. Decision analysis: practice and promise. Manage. Sci. 34, 679-695. Hurley, L., Ashley, R., Mounce, S., 2008. Addressing practical problems in sustainability assessment frameworks. Proceedings of the ICE-Engineering Sustainability 161, 23-30. Kaiser, F.G., Wilson, M., 2000. Assessing people's general ecological behavior: a cross-cultural measure. J. Appl. Soc. Psychol. 30, 952-978. DOI:10.1111/j.1559-1816.2000.tb02505.x Karvetski, C.W., Lambert, J.H., Keisler, J.M., Linkov, I., 2011. Integration of decision analysis and scenario planning for coastal engineering and climate change. Systems, Man and Cybernetics, Part A: Systems and Humans, IEEE Transactions on 41, 63-73.

Keeney, R.L., 1996. Value-focused thinking: Identifying decision opportunities and creating alternatives. Eur. J. Oper. Res. 92, 537-549. DOI:10.1016/0377-2217(96)00004-5 Keeney, R.L., Raiffa, H., 1976. Decisions with Multiple Objectives: preferences and value trade-offs. John Wiley and Sons, New York.

Keeney, R.L., Wood, E.F., 1977. An illustrative example of the use of multiattribute utility theory for water resource planning. Water Resour. Res. 13, 705-712.

Kendall, M.G., 1938. A new measure of rank correlation. Biometrika, 81-93.

Kiker, G.A., Bridges, T.S., Varghese, A., Seager, T.P., Linkov, I., 2005. Application of multicriteria decision analysis in environmental decision making. Int. Environ. Ass. Manage. 1, 95-108. DOI:10.1897/IEAM_2004a-015.1

Kim, Y., Chung, E.S., Jun, S.M., Sang, U.K., 2013. Prioritizing the best sites for treated wastewater instream use in an urban watershed using fuzzy TOPSIS. Resour. Conserv. Recy. 73, 23-32. DOI:10.1016/j.resconrec.2012.12.009

Lahdelma, R., Salminen, P., 2001. SMAA-2: stochastic multicriteria acceptability analysis for group decision making. Oper. Res. 49, 444-454. DOI:10.1287/opre.49.3.444.11220

Lahdelma, R., Salminen, P., 2012. The shape of the utility or value function in stochastic multicriteria acceptability analysis. Or Spectrum 34, 785-802. DOI:10.1007/s00291-011-0244-5 Langhans, S.D., Lienert, J., 2016. Four Common Simplifications of Multi-Criteria Decision Analysis do not hold for River Rehabilitation. Plos One 11. DOI:10.1371/journal.pone.0150695 Langhans, S.D., Reichert, P., Schuwirth, N., 2014. The method matters: a guide for indicator aggregation in ecological assessments. Ecol. Indic. 45, 494-507.

DOI:10.1016/j.ecolind.2014.05.014

Larsen, T.A., Alder, A.C., Eggen, R.I., Maurer, M., Lienert, J., 2009. Source separation: will we see a paradigm shift in wastewater handling? . Environ. Sci. Technol. 43, 6121-6125.

DOI:10.1021/es803001r

Larsen, T.A., Hoffmann, S., Luthi, C., Truffer, B., Maurer, M., 2016. Emerging solutions to the water challenges of an urbanizing world. Science 352, 928-933. DOI:10.1126/science.aad8641 Larsen, T.A., Udert, K.M., Lienert, J., 2013. Source Separation and Decentralization for Wastewater Management. IWA Publishing, London, UK.

Lienert, J., Duygan, M., Zheng, J., 2016. Preference stability over time with multiple elicitation methods to support wastewater infrastructure decision-making. Eur. J. Oper. Res. 253, 746760. DOI:10.1016/j.ejor.2016.03.010

Lienert, J., Koller, M., Konrad, J., McArdell, C.S., Schuwirth, N., 2011. Multiple-criteria decision analysis reveals high stakeholder preference to remove pharmaceuticals from hospital wastewater. Environ. Sci. Technol. 45, 3848-3857. DOI:10.1021/es1031294 Lienert, J., Larsen, T.A., 2010. High acceptance of urine source separation in seven European countries: a review. Environ. Sci. Technol. 44, 556-566. DOI:10.1021/es9028765 
Lienert, J., Schnetzer, F., Ingold, K., 2013. Stakeholder analysis combined with social network analysis provides fine-grained insights into water infrastructure planning processes. J. Environ. Manage. 125, 134-148. DOI:10.1016/j.jenvman.2013.03.052

Lienert, J., Scholten, L., Egger, C., Maurer, M., 2015. Structured decision-making for sustainable water infrastructure planning and four future scenarios. EUR. J. Decis. Process. 3, 107-140. DOI:10.1007/s40070-014-0030-0

Logar, I., Brouwer, R., Maurer, M., Ort, C., 2014. Cost-benefit analysis of the Swiss national policy on reducing micropollutants in treated wastewater. Environ. Sci. Technol. 48, 1250012508. DOI:10.1021/es502338j

Ip_solve, Kjell, K., 2014. IpSolveAPI: R Interface for Ip_solve version 5.5.2.0.

Macharis, C., Springael, J., 2004. PROMETHEE and AHP: The design of operational synergies in multicriteria analysis.: Strengthening PROMETHEE with ideas of AHP. Eur. J. Oper. Res.

153, 307-317. DOI:1016/S0377-2217(03)00153-X

Makropoulos, C.K., Butler, D., 2010. Distributed water infrastructure for sustainable communities. Water Resour. Manag. 24, 2795-2816. DOI:10.1007/s11269-010-9580-5

Maurer, M., Rothenberger, D., Larsen, T., 2005. Decentralised wastewater treatment technologies from a national perspective: at what cost are they competitive? Water Sci. Tech: W. Sup. 5, 145.

Milly, P.C.D., Betancourt, J., Falkenmark, M., Hirsch, R.M., Kundzewicz, Z.W., Lettenmaier, D.P., Stouffer, R.J., 2008. Stationarity is dead: whither water management? Science 319, 573574. DOI:10.1126/science. 1151915

Molinos-Senante, M., Gómez, T., Garrido-Baserba, M., Caballero, R., Sala-Garrido, R., 2014. Assessing the sustainability of small wastewater treatment systems: A composite indicator approach. Sci. Total Environ. 497-498, 607-617. DOI:10.1016/j.scitotenv.2014.08.026

Muga, H.E., Mihelcic, J.R., 2008. Sustainability of wastewater treatment technologies. J. Environ. Manage. 88, 437-447. DOI:10.1016/j.jenvman.2007.03.008

Mustajoki, J., Hämäläinen, R.P., Salo, A., 2005. Decision support by interval SMART/SWINGincorporating imprecision in the SMART and SWING methods. Decision Sci. 36, 317-339. DOI:10.1111/j.1540-5414.2005.00075.x

Pöyhönen, M., Vrolijk, H., Hämäläinen, R.P., 2001. Behavioral and procedural consequences of structural variation in value trees. Eur. J. Oper. Res. 134, 216-227. DOI:10.1016/S03772217(00)00255-1

R Core Team, 2014. R: A Language and Environment for Statistical Computing. R Foundation for Statistical Computing, Vienna, Austria.

Raju, K.S., Vasan, A., 2007. Multi attribute utility theory for irrigation system evaluation. Water Resour. Manag. 21, 717-728. DOI:10.1007/s11269-006-9060-0

Ram, C., Montibeller, G., 2013. Exploring the impact of evaluating strategic options in a scenario-based multi-criteria framework. Techn. Forecast. Soc. Change 80, 657-672.

DOI:10.1016/j.techfore.2012.09.019

Reed, M.S., 2008. Stakeholder participation for environmental management: a literature review. Biol. Conserv. 141, 2417-2431. DOI:10.1016/j.biocon.2008.07.014

Reichert, P., Schuwirth, N., Langhans, S., 2013. Constructing, evaluating and visualizing value and utility functions for decision support. Environ. Modell. Softw. 46, 283-291.

DOI:10.1016/j.envsoft.2013.01.017

Reichert, P., Schuwirth, N., Lienert, J., Langhans, S., 2015. The conceptual fundation of environmental decision support. J. Environ. Manage. 154, 316-332.

DOI:10.1016/j.jenvman.2015.01.053

Reynolds, J.H., Barrett, M.H., 2003. A review of the effects of sewer leakage on groundwater quality. Water Environ. J. 17, 34-39. DOI:10.1111/j.1747-6593.2003.tb00428.x

Rowley, H.V., Peters, G.M., Lundie, S., Moore, S.J., 2012. Aggregating sustainability indicators: beyond the weighted sum. J. Environ. Manage. 111, 24-33.

DOI:10.1016/j.jenvman.2012.05.004

Roy, B., 1996. Multicriteria methodology for decision aiding. Kluwer Academic Publishers, Dordrecht.

Saaty, T.L., 1980. The analytical hierarchical process. McGraw-Hill, New York.

Sægrov, S., 2005. Computer Aided Rehabilitation of Sewer and Storm Water Networks-CARE- 
S. IWA Publishing, London.

Schiller, G., Dirlich, S., 2015. Applications of life-cycle cost analysis in water and wastewater projects: lessons from European experience, in: Kurian, M., Ardakanian, R. (Eds.), Governing the Nexus. Springer International Publishing, pp. 131-151.

Scholten, L., Schuwirth, N., Reichert, P., Lienert, J., 2015. Tackling uncertainty in multi-criteria decision analysis - An application to water supply infrastructure planning. Eur. J. Oper. Res. 242, 243-260. DOI:10.1016/j.ejor.2014.09.044

Schuwirth, N., Reichert, P., Lienert, J., 2012a. Methodological aspects of multi-criteria decision analysis for policy support: a case study on pharmaceutical removal from hospital wastewater. Eur. J. Oper. Res. 220, 472-483. DOI:10.1016/j.ejor.2012.01.055

Schuwirth, N., Stamm, C., Reichert, P., 2012b. Incorporation of uncertainty in decision support to improve water quality, in: Seppelt, R., Voinov, A., Lange, S., Bankamp, D. (Eds.),

International Congress on Environmental Modelling and Software. Sixth Biennial Meeting, Leipzig, Germany.

Smith, J.E., Von Winterfeldt, D., 2004. Anniversary Article: Decision Analysis in Management Science. Manage. Sci. 50, 561-574. DOI:10.1287/mnsc.1040.0243

Stewart, T.J., French, S., Rios, J., 2013. Integrating multicriteria decision analysis and scenario planning-review and extension. Omega 41, 679-688. DOI:10.1016/j.omega.2012.09.003 ten Veldhuis, J.A.E., Clemens, F.H.L.R., Sterk, G., Berends, B.R., 2010. Microbial risks associated with exposure to pathogens in contaminated urban flood water. Water Res. 44, 2910-2918. DOI:10.1016/j.watres.2010.02.009

Tervonen, T., Lahdelma, R., 2007. Implementing stochastic multicriteria acceptability analysis.

Eur. J. Oper. Res. 178, 500-513. DOI:10.1016/j.ejor.2005.12.037

Ugarelli, R., Venkatesh, G., Brattebø, H., Di Federico, V., Sægrov, S., 2009. Asset

management for urban wastewater pipeline networks. J. Infrastruct. Syst. 16, 112-121.

Ülengin, F., İlker Topcu, Y., Şahin, Ş.Ö., 2001. An integrated decision aid system for Bosphorus water-crossing problem. Eur. J. Oper. Res. 134, 179-192. DOI:10.1016/S0377-2217(00)002472

Weyrauch, P., Matzinger, A., Pawlowsky-Reusing, E., Plume, S., von Seggern, D., Heinzmann, B., Schroeder, K., Rouault, P., 2010. Contribution of combined sewer overflows to trace contaminant loads in urban streams. Water Res. 44, 4451-4462.

DOI:10.1016/j.watres.2010.06.011

Willems, P., Olsson, J., Arnbjerg-Nielsen, K., 2012. Impacts of climate change on rainfall extremes and urban drainage systems. IWA Publishing, London.

Yang, J.S., Chung, E.S., Kim, S.U., Kim, T.W., 2011. Prioritization of water management under climate change and urbanization using multi-criteria decision making methods. Hydrol. Earth Syst. Sc. Discuss. 8, 801-814. DOI:10.5194/hess-16-801-2012 